\title{
Vibro-Acoustic Propagation of Gear Dynamics in a Gear-Bearing-Housing System
}

\author{
Yi Guo ${ }^{\mathrm{a}, *}$, Tugan Eritenel ${ }^{\mathrm{b}}$, Tristan M. Ericson ${ }^{\mathrm{c}}$, Robert G. Parker $^{\mathrm{d}}$ \\ ${ }^{a}$ National Renewable Energy Laboratory \\ 15013 Denver West Parkway, Golden, CO, 80401-3305 \\ ${ }^{b}$ Romax Technology Inc. \\ 2760 29th Street STE 2E, Boulder, CO, 80301 \\ ${ }^{c}$ Department of Physical Sciences \\ York College of Pennsylvania \\ York, $P A, 17403$ \\ ${ }^{d}$ Department of Mechanical Engineering \\ Virginia Tech \\ Blacksburg, VA, 24061
}

\begin{abstract}
This work developed a computational process to predict noise radiation from gearboxes. It developed a system-level vibro-acoustic model of an actual gearbox, including the gears, bearings, shafts, and housing structure, and compared the results to experiments. The meshing action of gear teeth causes vibrations to propagate through shafts and bearings to the housing radiating noise. The vibration excitation from the gear mesh and the system response were predicted using finite element and lumped-parameter models. From these results, the radiated noise was calculated using a boundary element model of the housing. Experimental vibration and noise measurements from the gearbox confirmed the computational predictions. This tool was used to investigate the influence of standard rolling element and modified journal bearings on gearbox radiated noise.
\end{abstract}

Keywords: Gearbox, noise propagation, vibro-acoustic, vibration, bearing

\section{Introduction}

Gearbox vibration originates mostly from the meshing action of the gear teeth. It is the primary source of interior cabin noise in helicopters [1] and an important noise source in automotive transmissions and wind turbines. Although gear vibration has been studied extensively, limited work has been done

${ }^{*}$ Corresponding author. National Renewable Energy Laboratory

15013 Denver West Parkway, Golden, CO 80401-3305, Tel.: +1-303-384-7187; Fax: +1-303-384-6901

Email address: yi.guo@nrel.gov (Yi Guo)

Preprint submitted to Journal of Sound and Vibration

April 9, 2014

(C) 2014. This manuscript version is made available under the Elsevier user license http://www.elsevier.com/open-access/userlicense/1.0/ 
to quantitatively examine the complete vibro-acoustic process starting from gear vibration excited by the meshing teeth to noise radiation from the housing.

Gearbox noise often contains a wide range of frequencies within the audible range. Advanced signal processing techniques have been applied to experimental vibro-acoustic analysis of helicopter gearboxes $[1,2,3,4,5]$ to identify the vibrations caused by gears, shafts, and bearings [6]. On the other hand, computational vibro-acoustic analysis of geared systems is sparse in the existing literature [7]. Structureborne gearbox noise originating from gear vibrations is often estimated empirically $[8,9]$. These acoustic estimates are specific to the experimental gearbox that was analyzed and may not be suitable for other gearboxes because the radiated noise depends strongly on the shape of the housing.

The objective of this effort is to build a new multiphysics process to predict the noise radiated from gearboxes. The vibration, which originates from the meshing gear teeth, is transmitted through the shafts and bearings to the housing and surrounding environment. The computational tools are finite element [10] and lumped-parameter [11] models for the entire gearbox, a finite element model for housing vibration, and a boundary element model for noise radiation [12]. The stiffness and damping characteristics of bearings

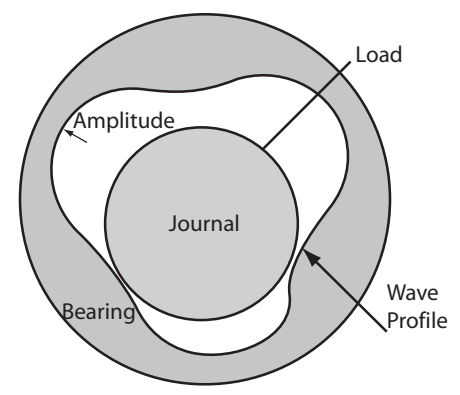

Figure 1: Sketch of a fluid film wave bearing. (The wave profile has been exaggerated for clarity.)

affect the transmissibility of vibration generated by the gears to the housing, which influences radiated noise.

In this study, two different bearing types were considered: rolling element and wave bearings. Wave bearings are journal bearings that have a wave profile that is machined on the inner surface of the bearing, as shown in Figure 1. The wave profile amplitude is in the order of micrometers and typically has three periods on the bearing race. Wave bearings can have higher load carrying capacity, higher stiffness and damping, and increased endurance when operating without oil than similar plain journal bearings [13]. Dimofte et al. $[14,15]$ compared the load capacity of wave and journal bearings analytically and experimentally and 
concluded that wave bearings are dynamically more stable than plain journal bearings under light-load or unloaded conditions. Wave bearings have been implemented in gas turbines [15, 16], and proposed for helicopter transmissions $[14,17,15]$. The computational procedure developed in this work was used to examine the effects on transmitted noise of wave bearings.

The scope of this study included: 1) build a finite element gearbox model to predict vibration excitation from the gear tooth mesh and its propagation through shafts and bearings; 2) develop a lumped-parameter dynamic model of the entire gearbox that is more computationally efficient than a finite element model; 3) establish a boundary element model of the gearbox housing to predict the radiated noise; 4) compare this combined model against experimental vibration and noise measurements and theoretical solutions in the literature; and 5) investigate the effect of replacing rolling element bearings with wave bearings on the vibro-acoustic transmission from the gears to the housing.

\section{Gearbox Description}

Figure 2 illustrates the physical gearbox considered. It is located at the National Aeronautics and Space Administration (NASA) Glenn Research Center and includes a pair of spur gears with webbed rims, two shafts, four bearings that support the shafts, and the housing, either rolling element or wave bearings. The gear parameters are listed in Table 1. Two types of rolling element bearings are used: cylindrical roller bearings and deep groove ball bearings. Table 2 gives the bearing parameters. The product designations are SKF N205ECP for the cylindrical bearings and SKF 6205 for the ball bearings. The ball bearings are used at the gearbox input/output shaft connections as shown in Figure 2. The cylindrical bearings support the other ends of the gear shafts. The dimensions of the wave bearings are given in Table 3 . The housing is rectangular with a height of $279.4 \mathrm{~mm}$, width of $254.0 \mathrm{~mm}$, and length of $330.2 \mathrm{~mm}$. The housing wall and lid thickness is $6.35 \mathrm{~mm}$. A torque of $79.1 \mathrm{~N}-\mathrm{m}$ is applied for experiments presented in this paper. This gearbox has been used in other experiments, and further details are included in $[18,13]$.

\section{Gearbox Vibro-Acoustic Propagation Analysis Method}

In this work, noise and vibration measurements from a simple gearbox and a housing are acquired. A combination of theoretical techniques were then used to model the physical phenomena observed in the experiments, namely, gear vibration, vibration propagation from the gears through the bearings, housing 


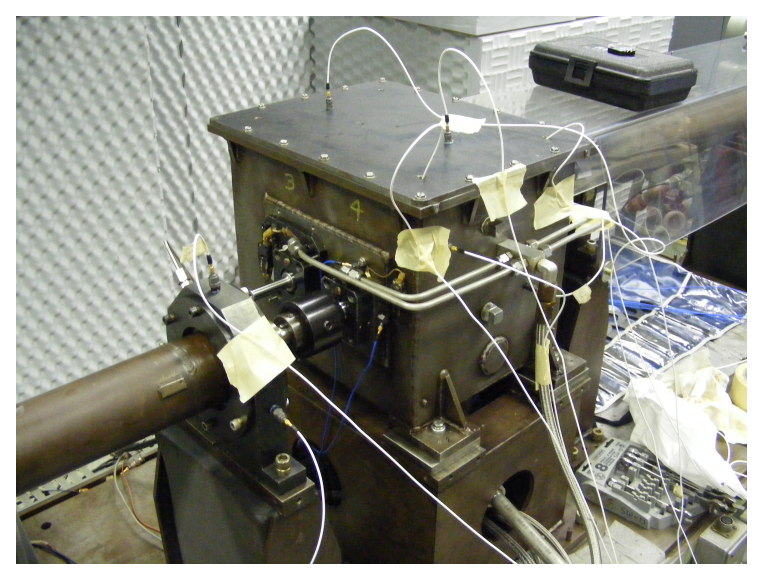

(a)



(b)

Figure 2: (a) Outside and (b) inside of the gearbox at the NASA Glenn Research Center.

\begin{tabular}{ll}
\hline Parameters & Values \\
\hline \hline Number of teeth & 28 \\
Outer diameter $(\mathrm{mm})$ & 95.25 \\
Root diameter $(\mathrm{mm})$ & 79.73 \\
Facewidth $(\mathrm{mm})$ & 6.35 \\
Module $(\mathrm{mm})$ & 3.18 \\
Pressure angle & $20^{\circ}$ \\
Center distance $(\mathrm{mm})$ & 88.90 \\
Tooth thickness $(\mathrm{mm})$ & 4.85 \\
Cutter edge radius $(\mathrm{mm})$ & 1.27 \\
Linear tip relief $(\mu \mathrm{m})$ & 18 starting at $24^{\circ}$ roll angle \\
\hline
\end{tabular}

Table 1: Experimental NASA test rig spur gear teeth parameters.

vibration, and acoustic emission from the housing surface. Figure 3 shows a schematic of how these models and experiment are connected.

Multiple interconnected models work together to calculate the gearbox vibration transmission and acoustic radiation. The models are: (A) a finite element/contact mechanics (FE/CM) model of the gearbox including the housing, (B) a lumped-parameter gearbox model, (C) a finite element model of only the housing; and (D) an acoustic boundary element model of the housing. The roles, inputs, and outputs of 


\begin{tabular}{lll}
\hline Parameters & Cylindrical Bearing & Ball Bearing \\
\hline \hline Number of rolling elements & 13 & 9 \\
Pitch diameter $(\mathrm{mm})$ & 39.0 & 38.5 \\
Bore diameter $(\mathrm{mm})$ & 25.0 & 25.0 \\
Roller length $(\mathrm{mm})$ & 8.60 & 7.90 \\
Roller diameter $(\mathrm{mm})$ & 7.50 & 7.90 \\
Bearing width $(\mathrm{mm})$ & 15.0 & 15.0 \\
Outer diameter $(\mathrm{mm})$ & 52.0 & 52.0 \\
Outer diameter of inner raceway $(\mathrm{mm})$ & 31.5 & 34.4 \\
Inner diameter of outer raceway $(\mathrm{mm})$ & 46.4 & 46.3 \\
Radial clearance $(\mu m)$ & 40 & 20 \\
Inner race crown curvature $(1 / \mathrm{mm})$ & $100 \times 10^{-9}$ & 0.52 \\
Outer race crown curvature $(1 / \mathrm{mm})$ & $100 \times 10^{-9}$ & 0.52 \\
\hline
\end{tabular}

Table 2: Cylindrical roller and ball bearing parameters. Cylindrical bearing parameters are based on SKF N205ECP. Ball bearing parameters are based on SKF 6205.

\begin{tabular}{ll}
\hline Parameters & Values \\
\hline \hline Number of waves & 3 \\
Bearing width $(\mathrm{mm})$ & 15.0 \\
Outer diameter $(\mathrm{mm})$ & 52.0 \\
Bearing inner diameter $(\mathrm{mm})$ & 32.0 \\
Radial clearance $(\mu \mathrm{m})$ & 15.0 \\
Wave amplitude $(\mu \mathrm{m})$ & 6.0 \\
\hline
\end{tabular}

Table 3: Basic dimensions of the wave bearings.

these models are described below.

The FE/CM model calculates the vibration excited by the gears and bearings. The meshing action of the gear teeth is the major excitation, so the success of the analysis hinges on the contact model's ability to capture the dynamic excitation from the gear mesh. The gear elasticity, deflections, and micron-level profile and lead modifications on the gear teeth are considered to accurately predict vibration excitation. In addition, the fluctuating bearing stiffnesses due to rollers coming in and out of contact excites vibration [19]. The bearing contact stiffness depends strongly on the macro- and micro-geometry of the raceways and rollers as well as the number of rollers in contact. A FE/CM model described in $[20,10,21,22,23,24]$ and implemented in the commercial software Calyx [10] was used in this work. The physical dimensions of the gears, shafts, and bearings are the only inputs of this model. The bearing roller/race and dynamic tooth mesh forces are calculated internally. The desired outputs are gear transmission error, bearing stiffnesses, 


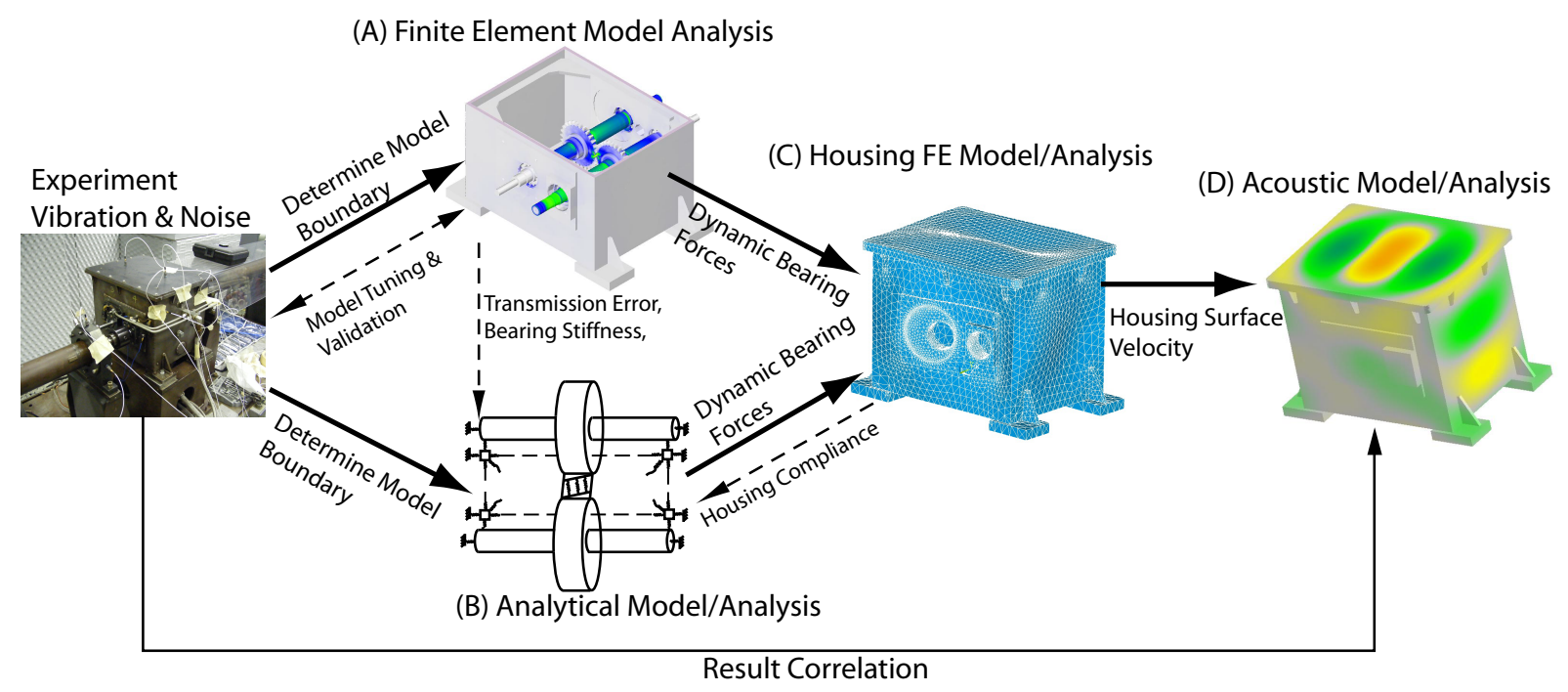

Figure 3: Model components of the gearbox acoustic analysis.

and bearing forces. These quantities are used in the lumped-parameter gearbox model (B) and finite element model of the housing (C). The FE/CM model (A) computes the dynamic response of the gearbox when simplified stiffness matrix models of the bearings are used. However, when complete contact models of the rolling element bearings, however, the dynamic analysis requires enormous computational effort.

In contrast to the FE/CM model (A), the lumped-parameter model (B) described in [11] provides an alternative method of dynamic analysis of the gearbox that is computationally efficient. Only one of these two models is needed. In both the FE/CM and lumped-parameter models, the gear model is threedimensional and captures tooth profile and lead modifications. The lumped-parameter model inputs are the gear mesh stiffness, bearing stiffness, and housing compliance from separate FE/CM analyses (A) and (C). The analysis outputs are dynamic bearing reaction forces, dynamic gear mesh force, and transmission error.

Finite element analysis of the housing (C) (established in ANSYS [25]) provides the housing compliance that is used in the lumped-parameter model (B) to capture the effects of housing deformation on gearbox vibration. The housing model also computes the housing surface velocities from the bearing dynamic reaction forces given by the FE/CM model or the lumped-parameter model.

The acoustic boundary element model (D) employs a multipole method [26] implemented in [12]. The inputs to the boundary element model are housing surface velocities from the finite element housing model (C). The outputs are the sound pressure level and velocity in the gearbox environment. 
Figure 4 describes the major steps of the vibro-acoustic propagation analysis procedure. As the first step, vibration and noise experiments were conducted to gather system damping and natural frequencies, and determine the mathematical modeling boundaries. Secondly, the FE/CM model (A) of entire gearbox system was established to determine bearing stiffness, gear transmission error, which were inputted into the lumped-parameter model (B). Both the FE/CM (A) and lumped-parameter (B) models calculated the dynamic bearing forces that were applied to the finite element housing model (C). Thirdly, vibration response and surface velocity of the housing were computed using the finite element housing model (C) with these dynamic bearing forces applied. At the end, the gearbox noise was computed using the boundary element housing model (D) with the calculated velocity applied.

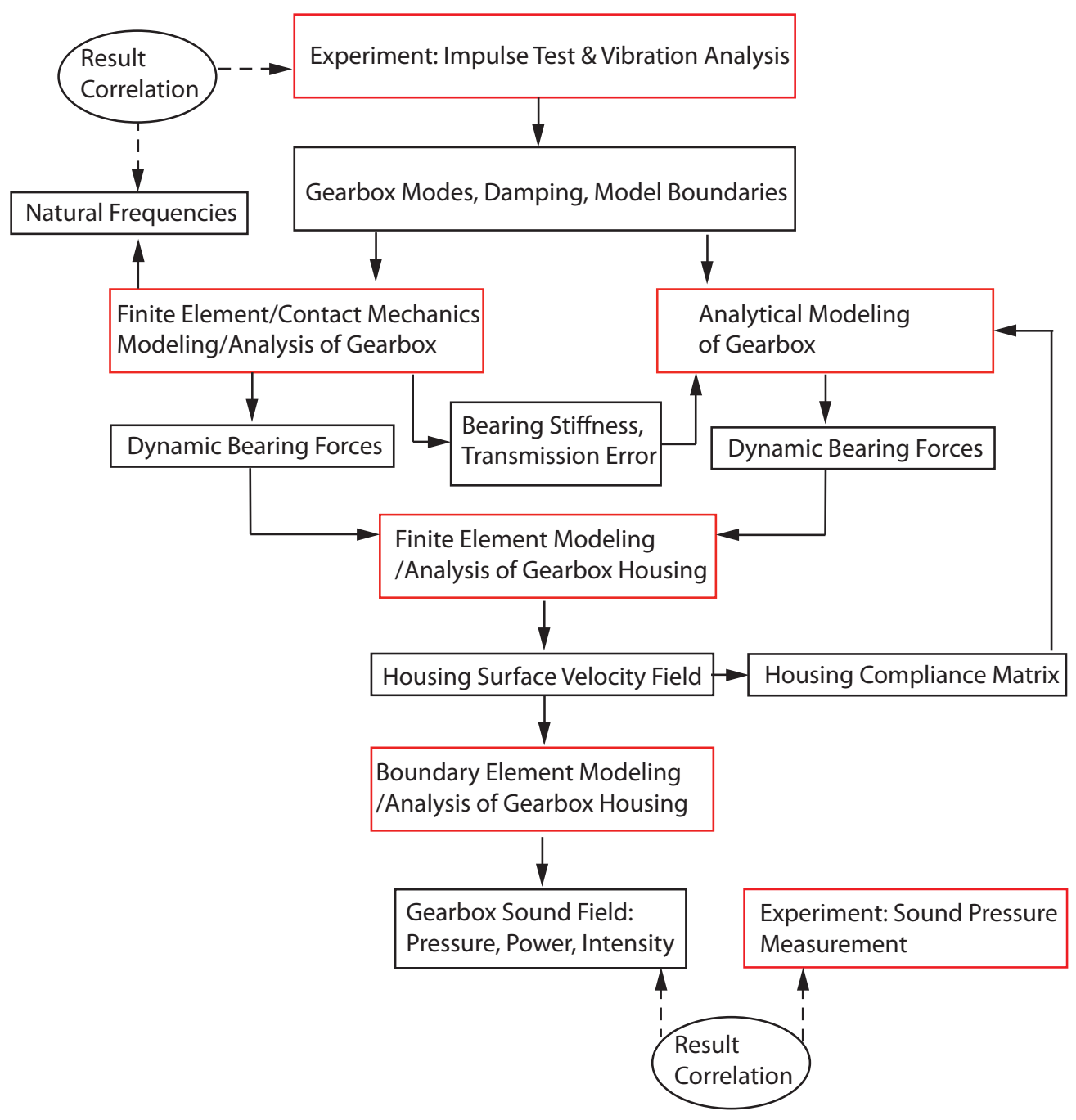

Figure 4: Flow chart of the gearbox acoustic analysis. 
The analysis methods summarized above are provided in greater detail as follows. The approach presented here can be implemented using any finite element, boundary element, or numerical simulation tools.

\subsection{Experiment}

Impulse test experiments were conducted to measure the frequency response of the gear test rig to validate the FE/CM model (A). These tests are used to understand the boundary conditions; quantify vibration transmissibility through the bearings; evaluate finite element results of the vibrating gears; estimate the modal damping ratios, and obtain the natural frequencies of the housing structure.

A standard impact hammer with an internal force transducer provided a measured input excitation. A static torque was applied to the system to simulate operational gear tooth stress conditions and keep the gears in contact during the experiments. Accelerometers gave the dynamic response. The measured input and output yielded the system transfer functions and dynamic characteristics. Figure 5 shows a schematic of the NASA gear test rig and identifies the locations of the accelerometers mounted in and around the gearbox. Accelerometers A1 and A2 are mounted vertically and horizontally to the input shaft pillow block; A3 and A4 are mounted to the sides of the gearbox; A5 and A6 are positioned vertically on the gearbox pinion shaft; A7 and A8 are positioned vertically on the system input shaft; and A9 and A10 are mounted to the gearbox cover. We performed impulse tests throughout the system and show results from four of them. Figure 6 identifies the impact locations on: (a) the rig input shaft, (b) a gear tooth, (c) the front of the gearbox, and $(d)$ the top of the gearbox. Three impacts were averaged for each test.

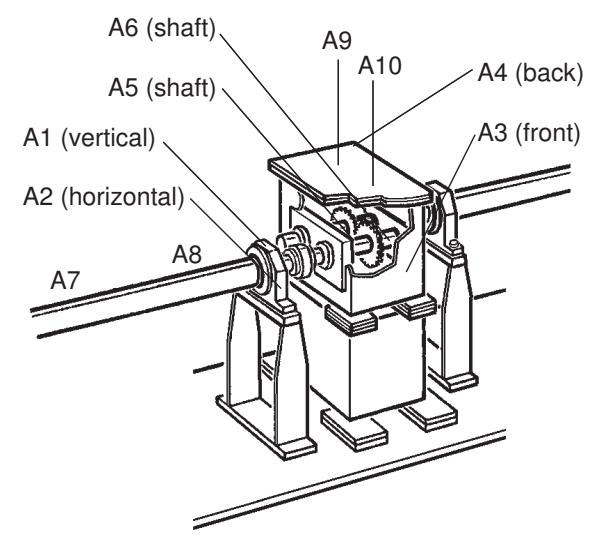

Figure 5: Accelerometers mounted on the input shaft pillow block (A1 and A2); the sides of the gearbox (A3 and A4); the pinion shaft (A5 and A6); the power transmission input shaft (A7 and A9); and the top of the gearbox (A9 and A10). 


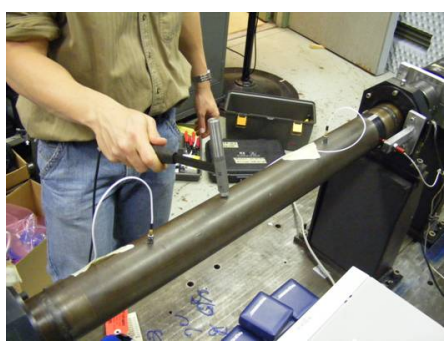

(a)

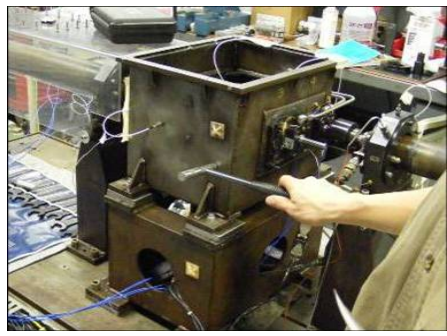

(c)

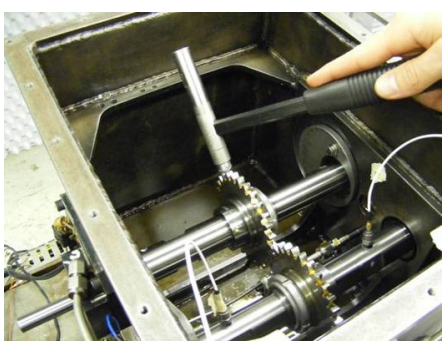

(b)

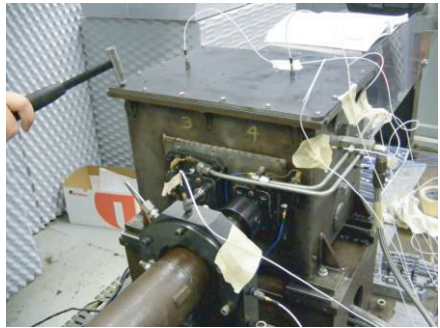

(d)

Figure 6: Impact locations for the relevant tests included: (a) the rig input shaft with accelerometers A7 and A8; (b) a gear tooth with accelerometers A5 and A6 mounted to the pinion shaft; (c) the side of the gearbox housing with accelerometer A4; and (d) the top of the gearbox housing with accelerometers A9 and A10.

These impulse test experiments were used to define the boundary conditions for the computer models by measuring the vibration transmissibility between internal gearbox components and the connecting test rig shafts, drive motor, and dynamometer. Figure 7 shows five distinct natural frequencies of the input shaft between 3050-4500 $\mathrm{Hz}$ measured by A7 and A8 from an impulse to that shaft illustrated in Figure 6(a). These natural frequencies are within the frequency range of expected gear dynamics. Therefore, if the input shaft is dynamically coupled with the gearbox system, it must be modeled. Accelerometers A1 and A2 mounted to the input shaft pillow block (Figure 5), however, did not pick up any of the input shaft modes. Additionally, Figure 11 shows different natural frequencies inside the gearbox associated with vibration of the gears and their shafts from impulse tests at a gear tooth, Figure 6(b). Vibration of these internal parts was also not passed through the pillow block bearings (A1 and A2) to accessory test stand components. Therefore, the dynamics of outside accessory parts (Figure 7) and inside gearbox components (Figure 11) are not strongly coupled.

The impulse test experiments in Figures 7 and 11 established the appropriate spatial boundaries of the system and show what parts are important for accurate modeling in the FE/CM and lumped-parameter models. While the gears, shafts, bearings, and housing are coupled, it is apparent that the connecting 


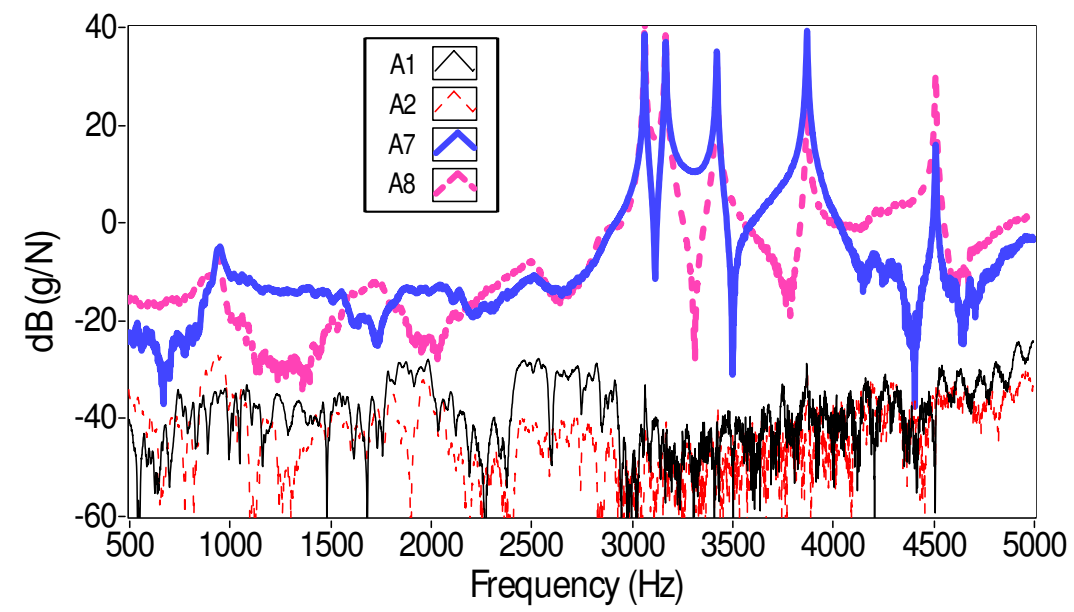

Figure 7: Frequency response functions for the impact test to the gearbox input shaft; Figure 6(a), with accelerometers A1 (thin -) and A2 (thin --) mounted to the input shaft and accelerometers A7 (thick -) and A8 (thick --) mounted to the input shaft pillow block as noted in Figure 5. The applied torque is $79.1 \mathrm{~N}-\mathrm{m}$.

input/output shafts, pillow blocks, drive motor, and dynamometer are decoupled and do not contribute to the dynamic behavior of the gearbox system. This indicates that the couplings just outside the gearbox housing are the proper vibration boundaries of the system. Thus, the input shaft connecting the motor to the gearbox and, similarly, the output shaft connecting the gearbox to the output dynamometer were not modeled.

\subsection{Model (A): Finite Element/Contact Mechanics Modeling and Analysis of the Gearbox}

The FE/CM model analyzes gear tooth contact and rolling element contact by using a combined analytical/finite element analysis. The analytical solution near the contacting surfaces captures the micron level details of the contacting gear and bearing surfaces. The elastic deformations of the gears and bearings away from the contacting surfaces are calculated using conventional finite element analysis. Each gear tooth is considered identical without any profile or positioning error. Details about this model are given in $[20,10]$ with additional description in $[22,21,24]$. Figures $8(\mathrm{a})$ and $8(\mathrm{~b})$ show the von Mises stress on the gears at an instant and the contact pressure pattern over one mesh cycle given by the model. The von Mises stress on a bearing and the contact stress on a roller are shown in Figures 9(a) and 9(b). Figure 10 shows the complete gearbox FE/CM model including the gear pair, rolling element bearings, shafts, and housing.

When the gears and bearing rolling elements rotate, the number of teeth and rolling elements in contact change, as do the location, size, and shape of the contact areas. These changes are important because they affect bearing forces, gear tooth loads, the transmission error, and the mesh and bearing 




(a)

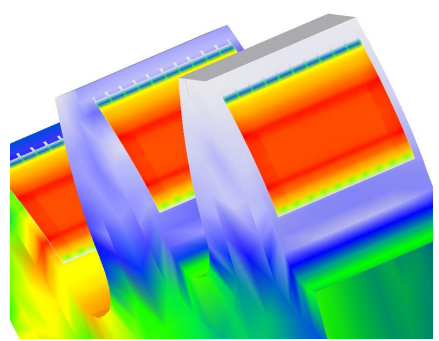

(b)

Figure 8: (a) Stress distribution of mating gears in the NASA experimental gearbox; (b) contact stress on gear teeth over one mesh cycle.



(a)



(b)

Figure 9: (a) Finite element model of a double row cylindrical bearing (outer race is removed); (b) contact pressure on one roller.

stiffness parameters. These parametric fluctuations are sources of vibration excitation. The finite element model captures the parametric fluctuations by updating the gear and bearing contact conditions at every time instant. Hence, mesh stiffness variation (and the closely connected static transmission error) and bearing stiffness variation are inherently included and not externally specified.

The FE/CM model was compared against studies of gear dynamics $[22,21,23,27,28,29,30]$. It captures the complex tooth mesh forces that lead to nonlinearity in the dynamics of single gear pairs [21], idler systems [29], two-stage geartrains [28, 31, 32], and planetary gears [22, 23, 27, 33, 30]. The model has been validated against experiments $[21,19,34]$ and compared to other gear models $[22,23,27,28,29,35]$ in various applications. The bearing rolling element contact has been validated against experiments in [19]. Planetary load sharing computed using the contact analysis has been correlated with experiments 


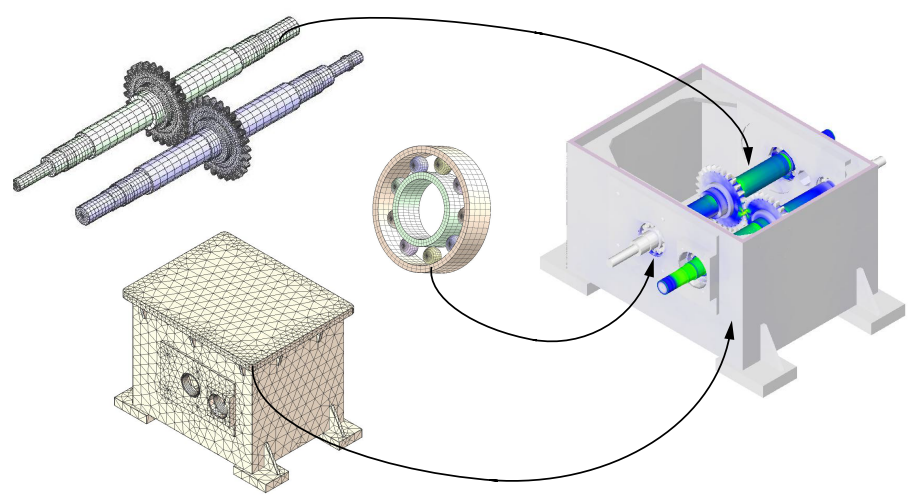

Figure 10: Assembly of the gear-bearing-shaft-housing model (A).

in [34]. The gearbox shafts introduce system compliance, which could cause misalignment and affect the vibration. The finite element model including shafts has been validated against Euler beam theory in [36].

\subsubsection{Validation of Model (A) by Vibration Experiments}

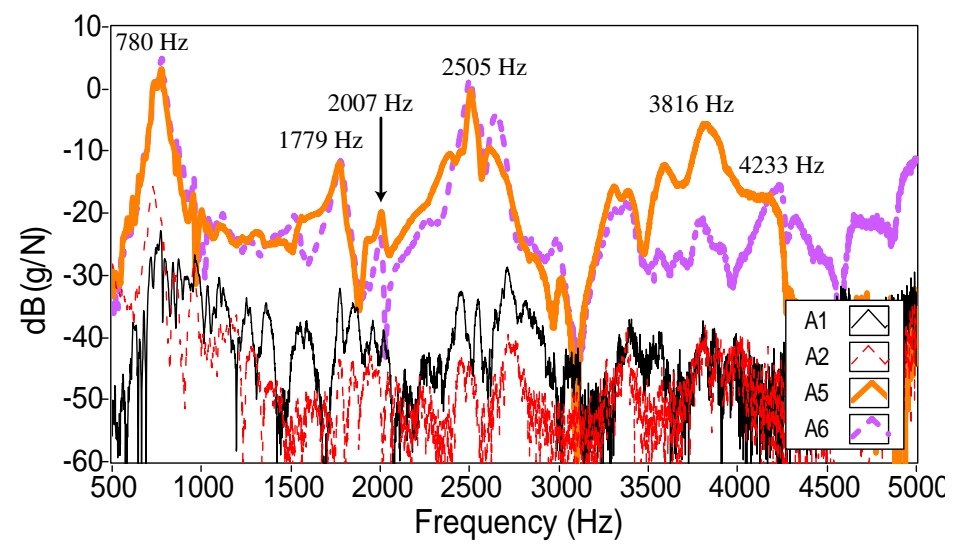

Figure 11: Frequency response functions for the impact test on a gear tooth; Figure 6(b), with accelerometers A1 (thin -) and A2 (thin --) mounted to the pinion shaft and accelerometers A5 (thick -) and A6 (thick --) mounted to the input shaft pillow block as noted in Figure 5. The applied torque is $79.1 \mathrm{~N}-\mathrm{m}$.

The natural frequencies observed in Figure 11 inside the gearbox can also be compared to results from the FE/CM model (A). Modal analysis was performed numerically on the finite element gearbox model by applying a torque impulse at the input shaft coupling and calculating the gear/shaft dynamic response. Spectra from this numerical impulse test gave the natural frequencies of the gearbox. Figure 12 shows the frequency spectra of: (a) the dynamic transmission error, and (b) the shaft displacement for the frequency range from 0-8000 $\mathrm{Hz}$. Table 4 compares the computed natural frequencies of modes with measurable shaft deflection to the experimental results in Figure 11. In the experiments, the gearbox cover was removed to 
provide excitation on the gear teeth (Figure 6 (b)), but the FE/CM simulation considers the cover because it would naturally be installed while the gears are spinning. All of the measured natural frequencies agree within $10 \%$. Removing the gearbox cover in the simulation would likely improve the correlation because most of the natural frequencies are overestimated, but we ultimately want to focus on the system with the cover. Damping ratios calculated from the half-power amplitudes in experiments [37] are also given in Table 4.

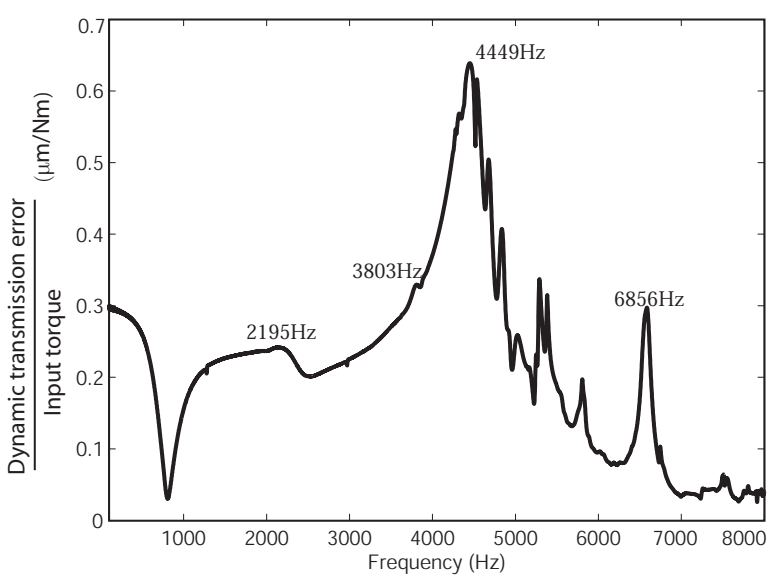

(a)

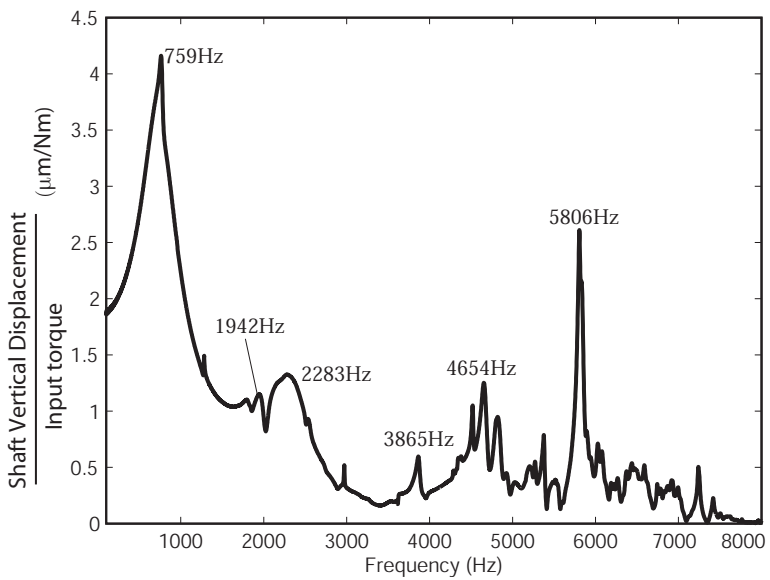

(b)

Figure 12: Finite element impulse test results of (a) dynamic transmission error, and (b) the pinion shaft horizontal displacement of the gear-bearing-housing system within the frequency range from 0 to $8000 \mathrm{~Hz}$. The applied torque is $79.1 \mathrm{~N}$ - $\mathrm{m}$.

\begin{tabular}{cccc}
\hline Experiments $(\mathrm{Hz})$ & Finite Element $(\mathrm{Hz})$ & Difference & Damping \\
\hline \hline 780 & 759 & $-2.9 \%$ & $3.6 \%$ \\
1779 & 1942 & $9.2 \%$ & $2.6 \%$ \\
2007 & 2195 & $9.4 \%$ & $2.7 \%$ \\
2504 & 2283 & $-8.8 \%$ & $1.5 \%$ \\
3816 & 3865 & $1.3 \%$ & $3.3 \%$ \\
4233 & 4449 & $5.1 \%$ & $2.2 \%$ \\
\hline
\end{tabular}

Table 4: Natural frequencies containing measurable pinion shaft vibration obtained by experimental impulse tests compared to FE/CM modeling.

Gearbox housing natural frequencies were measured experimentally and compared to finite element results. The gearbox cover was included in both experiments and computer simulation. Figure 13 shows the dynamic response of the gearbox housing to experimental impulse tests on the side and top of the gearbox housing as illustrated in Figures 6(c) and (d), respectively. Accelerometers A3 and A4 are mounted to the side of the gearbox housing while accelerometers A9 and A10 are mounted to the top cover. The 


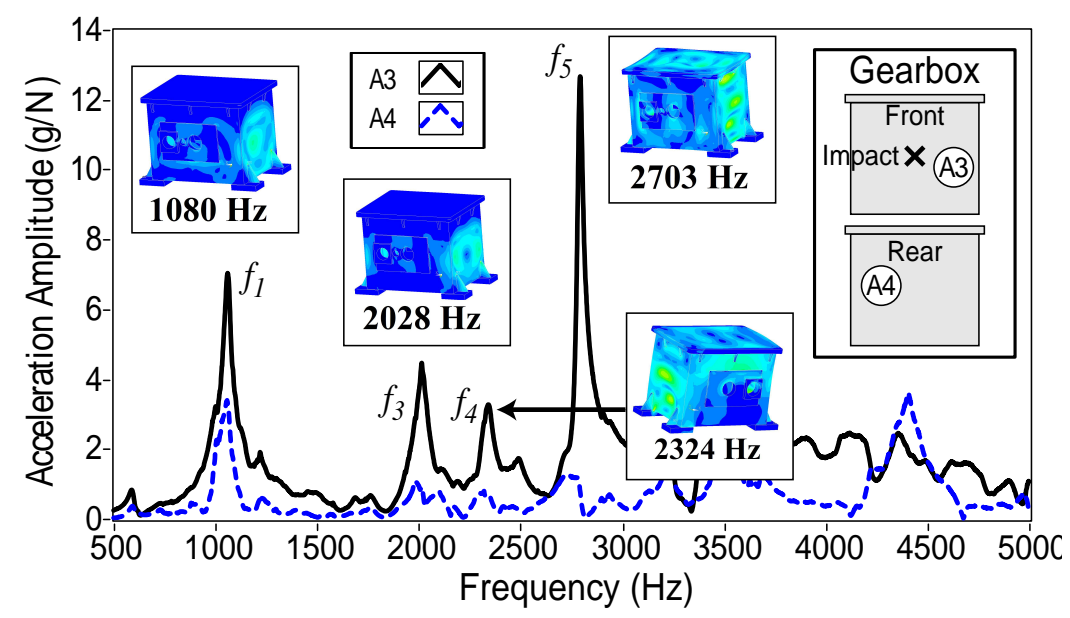

(a)

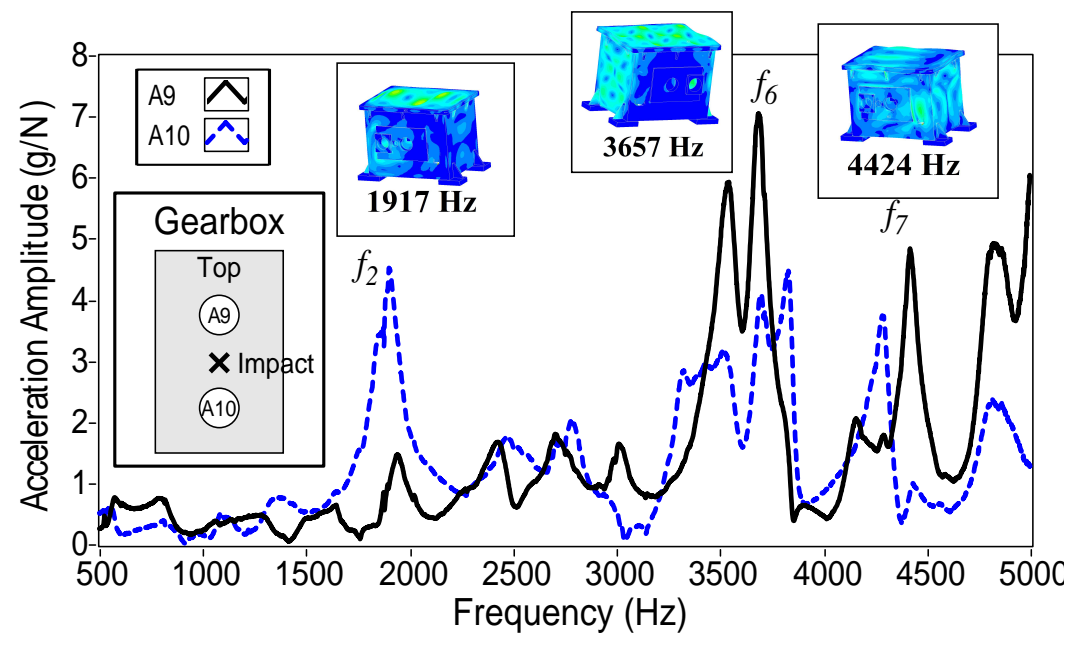

(b)

Figure 13: Gearbox frequency response functions in (a) the sides of the housing with accelerometers A3 (-) and A4 (--) and (b) the top of the housing with accelerometers A9 (-) and A10 (--) from impulse test experiments. Accelerometer locations are also noted in Figure 5. The inserted images show the corresponding mode shapes from finite element modeling. The applied torque is $79.1 \mathrm{~N}-\mathrm{m}$.

natural frequencies are collected in Table 5 and compared against finite element modeling. The mode shapes from the finite element model are shown in the inset pictures at the experimental frequency peaks in Figure 13. The model and experiments both show natural frequencies associated with modes having elastic deformations in the sides of the housing in Figure 13(a) and in the top of the housing in Figure 13(b). Results from computer simulations are only shown in the pictures. The data in Figure 13 (including all curves) are experimental. Table 5 shows that all seven natural frequencies agree between the experiments and the model within 4\%. Damping ratios of the gearbox housing modes calculated from experiments are 
also given. The average of the measured modal damping is used in the lumped-parameter model (B) in this study.

\begin{tabular}{ccccc}
\hline Mode & Experiments $(H z)$ & Finite Element $(H z)$ & Difference & Damping \\
\hline \hline 1 & 1059 & 1080 & $2.0 \%$ & $2.0 \%$ \\
2 & 1900 & 1917 & $0.9 \%$ & $2.6 \%$ \\
3 & 2015 & 2028 & $0.6 \%$ & $1.3 \%$ \\
4 & 2344 & 2324 & $-0.9 \%$ & $1.2 \%$ \\
5 & 2791 & 2703 & $-3.2 \%$ & $0.5 \%$ \\
6 & 3686 & 3686 & $1.0 \%$ & $1.0 \%$ \\
7 & 4417 & 4417 & $0.8 \%$ & $0.8 \%$ \\
\hline
\end{tabular}

Table 5: Natural frequencies of the gearbox housing obtained by experimental impulse tests compared to finite element modeling.

\subsubsection{Calculation of Rolling Element Bearing Stiffness Using the FE/CM Model}

Bearing stiffness is a crucial parameter because the bearings transmit vibration from the gears to the housing. Results in [19] show discrepancy in the nonlinear stiffness-load relations of the cylindrical and radial ball bearings calculated using the methods of Harris [38], Gargiulo [39], and While [40]. The microgeometry of the bearing raceways is neglected in these models. The differing assumptions that analytical models $[38,41,42,43]$ make about the race elasticity contribute to the discrepancy in their stiffness estimates.

The method in [19] to calculate static bearing stiffness has been validated against experiments [44, 45] and is adopted in this work because it includes raceway microgeometry and is more accurate than [38, 39, 40]. It gives the fully populated $6 \times 6$ bearing stiffness matrix using the numerical Jacobian of the load-deflection relation. This load-deflection relation is a natural output of the FE/CM analysis and avoids many of the assumptions of $[38,39,40]$.

Bearing stiffness is conventionally represented by a diagonal stiffness matrix. The calculation method used in this work, however, yields a fully populated stiffness matrix that includes the off-diagonal terms. Off-diagonal stiffnesses arise from coupling between the shaft tilting motion, the flexural motion of the housing connected to the outer race, and the shaft radial and axial motions. While common in many systems, this coupling was specifically seen in two experiments related to the transmission systems motivating this work [46, 47]. The effects of off-diagonal terms on the gearbox vibration transmissibility through rolling element bearings are highlighted below for the examined gearbox. 
The gear dynamic transmission error is defined as $r_{p} \beta_{p}-r_{g} \beta_{g}$, where $r_{p, g}$ are base radii of the gears and $\beta_{p, g}$ are gear rotations about $z$. Transmission error is an important measure of gearbox vibration. Figure 14 shows the spectra of dynamic transmission error in the frequency range 1500-4000 $\mathrm{Hz}$ from computational torque impulse tests using the fully populated and diagonal bearing stiffness matrices. There are obvious differences in resonant frequencies and amplitudes for the results with the fully populated and diagonal stiffness matrices, which demonstrates the importance of including fully populated bearing stiffness matrices in the gearbox modeling.

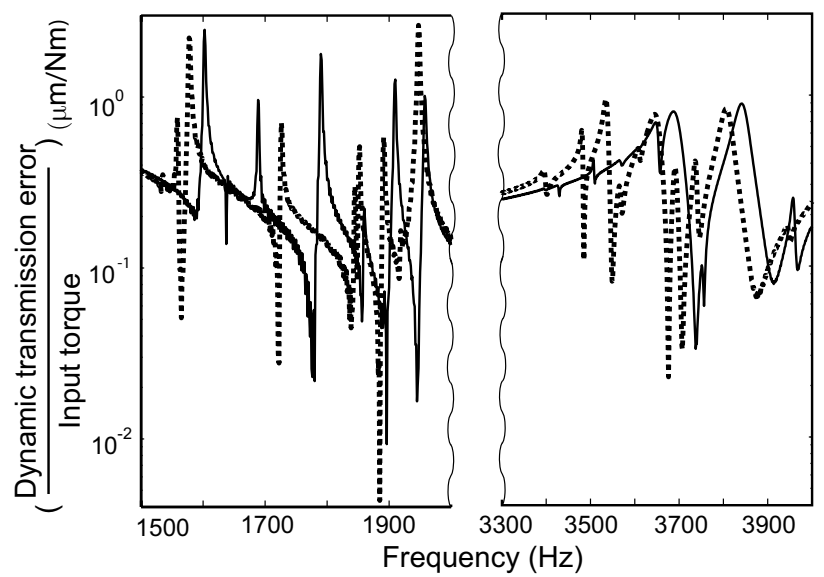

Figure 14: Numerical torque impulse response of gear dynamic transmission error with fully populated (-) and diagonal (--) stiffness matrices of the rolling element bearings. The input torque is $84.7 \mathrm{~N}-\mathrm{m}$.

\subsubsection{Fluid Film Wave Bearing Modeling}

The wave bearings are included in the gearbox model through the stiffness and damping matrices calculated using the approach developed by Hanford and Campbell [48, 49]. This wave bearing model applies a perturbation method to the Reynold's equation to calculate the stiffness, damping, pressure distribution, and load capacity of the fluid film bearing. The method is two-dimensional and excludes the tilting motions $\phi$ and $\theta$.

\subsection{Lumped-Parameter Dynamic Modeling (B) and Analysis of the Gearbox}

Dynamic analysis of the gearbox using a lumped-parameter model provides an alternative to the FE/CM model (A). Dynamic analysis using the finite element model is computationally expensive, which makes finite element analysis unfeasible for simulating speed-sweeps. The lumped-parameter model gives dynamic bearing reaction forces, dynamic transmission error, natural frequencies, and mode shapes. 
The lumped-parameter model described below employs information from static transmission error, mesh stiffness, bearing stiffness, and housing compliance obtained from static finite element analysis that is computed once and not repeated for different speeds, torques, and tooth modifications.

\subsubsection{Gear Pair}

The gear pair model follows [11], which is constructed based on the research of $[50,51,52,53,54,55]$. The model consists of two gears on shafts, with each of the gear-shaft bodies being a rigid body that admits motion in three-dimensional space with six degrees-of-freedom. Discussions on the validity of the gear mesh modeling can be found in $[11,56,50,51,52,54,55]$. These gear-shaft bodies are each mounted on two bearings described by fully populated $6 \times 6$ stiffness matrices. These bearings are connected to a flexible housing as described later.

Figure 15 shows the gear-shaft bodies, positioning of the bearings, and the bases. The right-hand, orthonormal basis is such that $\{\mathbf{E}\}=\left\{\mathbf{E}_{1}, \mathbf{E}_{2}, \mathbf{E}_{3}\right\}$ is oriented with $\mathbf{E}_{1}$ parallel to the line of action of the gear mesh. The origin is on the rotation axis of the pinion body, which is midpoint in the active facewidth. The translational $\left(x_{p}, y_{p}, z_{p}\right)$ and angular $\left(\phi_{p}, \theta_{p}, \beta_{p}\right)$ coordinates of the pinion body are assigned to translations along and rotations about $\mathbf{E}_{1}, \mathbf{E}_{2}$, and $\mathbf{E}_{3}$, respectively. The translational and angular coordinates of the gear body follow similarly with subscript $g$. Body-fixed bases $\left\{\mathbf{e}^{p}\right\}=\left\{\mathbf{e}_{1}^{p}, \mathbf{e}_{2}^{p}, \mathbf{e}_{3}^{p}\right\}$ and $\left\{\mathbf{e}^{g}\right\}=\left\{\mathbf{e}_{1}^{g}, \mathbf{e}_{2}^{g}, \mathbf{e}_{3}^{g}\right\}$ for the pinion and gear are adopted. Positive axial quantities are measured along $\mathbf{E}_{3}$ from the dashed line in Figure 15. The two bearings of the pinion body are named $A_{p}$ and $B_{p}$, and the two bearings of the gear body are named $A_{g}$ and $B_{g}$. The quantities $L_{p}^{A}, L_{p}^{B}, L_{g}^{A}$, and $L_{g}^{B}$ denote the axial locations of these bearings along the gear-shaft bodies. The operating pressure angle is $\Phi$; the base radii are $r_{p}$ and $r_{g}$; and the mass centers are denoted by $e_{p}$ and $e_{g}$.

This work considered spur gears and included profile modifications. The gear contact force, therefore is not equally distributed along the gear face, but varies along the facewidth. To capture this contact force distribution along the gear face, the distributed load along each gear tooth contact line is discretized by a network of piecewise linear springs acting at a contact point denoted by $C_{i}$ in Figure 15 . The coordinates of these contact points are $b_{i}$ along $\mathbf{E}_{1}$ and $c_{i}$ along $\mathbf{E}_{3}$. The axial coordinate $c_{i}(t)$ is measured from the origin along $\mathbf{E}_{3}$, and radial coordinate $b_{i}(t)$ is measured from the origin along $-\mathbf{E}_{1}$. The positions of a contact point are known functions of time determined by the contact line progressions as the gears rotate. Micron-level deviations of the tooth surface from an involute at any contact point $i$, such as from gear tooth surface modifications and manufacturing errors, are denoted by $h_{i}$. Figures 15 and 16 show these 

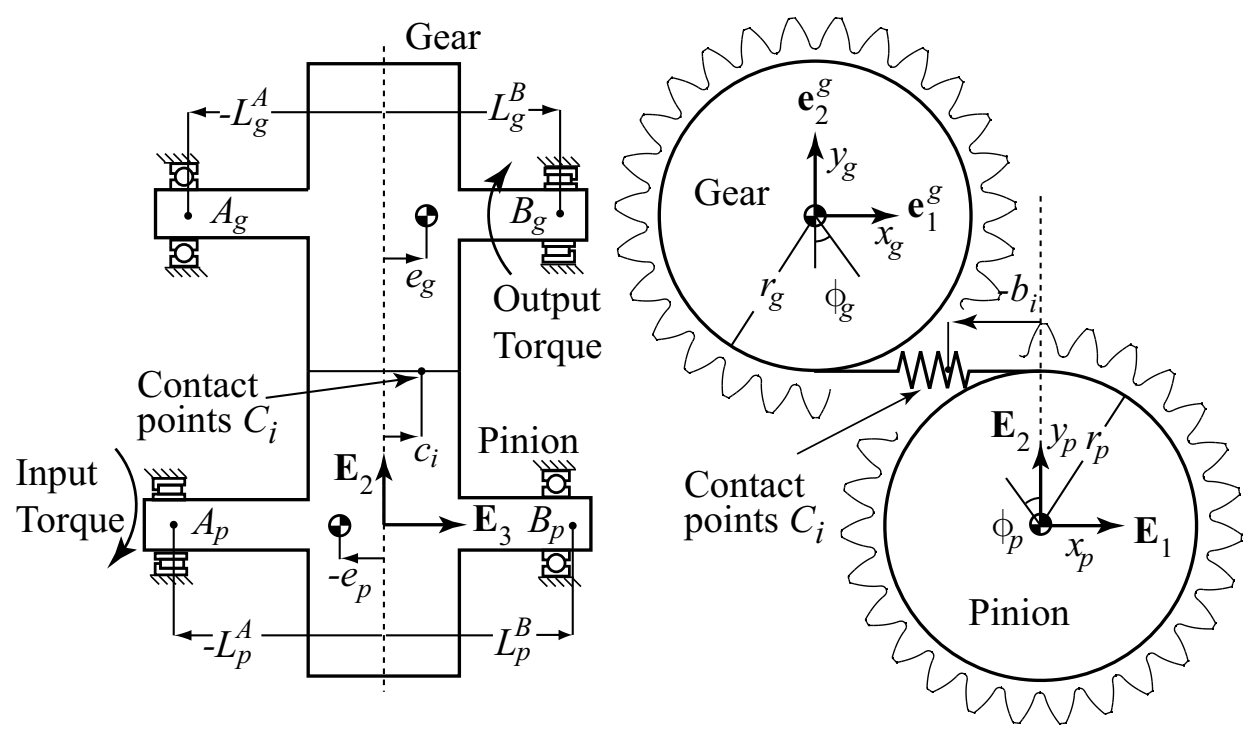

Figure 15: A lumped-parameter model of the gear pair. All positive axial quantities are measured along $\mathbf{E}_{\mathbf{3}}$ from the dashed line, which is at the center of the active facewidth. All positive tangential quantities are measured along $\mathbf{E}_{\mathbf{1}}$ from the dashed line located at the pinion mass center [11].

quantities.

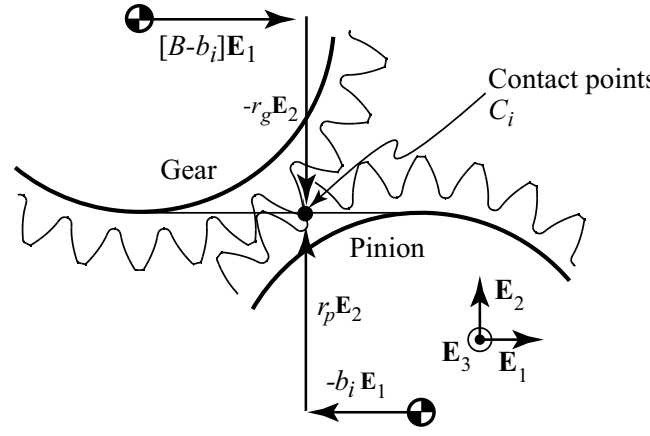

(a)



(b)

Figure 16: Distributed load and the position vectors from the pinion and gear mass centers. (a) Side view, (b) top view. [11]

The contact lines evolve as the gears rotate, changing their length and location on the gear tooth surface. With displacements of the gear bodies, the contact points on the pinion separate or compress against the contact points on the gear. The difference between the position vectors of the contact points on the pinion and gear gives the relative mesh deflection vector at points $C_{i}$. The projection of the relative mesh deflection vector in the direction of the tooth surface normal gives the relative compressive deflection 
at the $i^{\text {th }}$ contact point, which is

$$
\begin{aligned}
\delta_{i} & =\left\{\left[e_{p}-c_{i}(t)\right] \theta_{p}+\left[c_{i}(t)-e_{g}\right] \theta_{g}-x_{p}+x_{g}+h_{i}+\beta_{p} r_{p}+\beta_{g} r_{g}\right\} \cos \psi \\
& -\left\{\left[b_{i}(t)+h_{i}\right] \theta_{p}+\left[\left(r_{p}+r_{g}\right) \theta_{g} \tan \Phi-b_{i}(t)\right]+z_{p}-z_{g}+\phi_{p} r_{p}+\phi_{g} r_{g}\right\} \sin \psi
\end{aligned}
$$

where $\psi$ is the base helix angle.

Each contact spring, with stiffness $k_{i}$, is attached to its contact point $C_{i}$. Each contact stiffness $k_{i}$ is obtained by considering two separate categories of tooth deflection, contact $\left(\epsilon_{i}\right)$ and bulk $\left(\delta_{b}\right)$, as described in $[54,11,57,58,59,60]$. The contact stiffness $k_{c}$ approximates the flexibility of contacting gear flanks. The contact stiffness is defined per unit contact length. Contact is lost if the contact deflection $\epsilon_{i}$ is negative. The bulk stiffness $k_{b}$ approximates the combined flexibility of the gear rim and the gear blank. The bulk stiffness is assumed constant. The contact stiffnesses are in parallel with each other, and the bulk stiffness is in series with all the contact stiffnesses. As a result, the total deflection at the $i^{\text {th }}$ contact point $C_{i}$ is the sum of the contact and bulk deflections, given by $\delta_{i}=\epsilon_{i}+\delta_{b}$, and the total mesh force $F$ is the sum of the contact stiffness forces (and equal to the bulk stiffness force). All contact segments have a known contact length $l(t)$, which is a function of time because the total contact length depends on the instantaneous gear positions and gear dimensions $[61,62,63]$. The mesh force for all segments is

$$
F=\sum_{i=1}^{n} F_{i}=k_{c} l(t) \sum_{i=1}^{n} \epsilon_{i} H\left(\epsilon_{i}\right)=k_{b} \delta_{b}, \quad H\left(\epsilon_{i}\right)=\left\{\begin{array}{cc}
1 ; & \epsilon_{i} \geq 0 \\
0 ; & \epsilon_{i}<0
\end{array}\right.
$$

Each contact stiffness is given by

$$
k_{i}=\frac{k_{b} k_{c} l(t) H\left(\epsilon_{i}\right)}{k_{b}+k_{c} l(t) \sum_{i=1}^{n(t)} H\left(\epsilon_{i}\right)}
$$

The contact stiffness per unit length $k_{c}$ and the bulk stiffness $k_{b}$ are parameters of the gear pair determined by the contact mechanics and elasticity of the gears. These constants can be approximated $[55,57,59,60]$. In this work, $k_{c}$ and $k_{b}$ are solved for from the static deflections obtained from finite element analysis $[20,10]$. In this case, $k_{c}$ and $k_{b}$ are numerical values that best fit the deflection obtained from the finite element analysis of gears, as explained in [11].

The potential energy stored in the gear mesh is

$$
V_{m e s h}=\frac{1}{2} \sum_{i=1}^{n(t)} k_{i} \delta_{i}^{2}
$$


where $n(t)$ is the number of contact segments at an instant $t$. The contact stiffness and the number of teeth in contact change as the gears rotate.

The inertia tensors of the axisymmetric pinion and gear bodies are $\mathbf{J}_{p}=\operatorname{diag}\left[J_{p}^{x}, J_{p}^{x}, J_{p}^{z}\right]$ and $\mathbf{J}_{g}=$ $\operatorname{diag}\left[J_{g}^{x}, J_{g}^{x}, J_{g}^{z}\right]$. The pinion translational and angular velocity vectors are

$$
\begin{aligned}
\dot{\mathbf{r}}_{p} & =\dot{x}_{p} \mathbf{E}_{1}+\dot{y}_{p} \mathbf{E}_{2}+\dot{z}_{p} \mathbf{E}_{3} \\
\boldsymbol{\omega}_{p} & =\left[\dot{\phi}_{p}-\theta_{p}\left(\dot{\beta}_{p}+\Omega_{p}\right)\right] \mathbf{e}_{1}^{p}+\left[\dot{\theta}_{p}+\phi_{p}\left(\dot{\beta}_{p}+\Omega_{p}\right)\right] \mathbf{e}_{2}^{p}+\left[\dot{\beta}_{p}+\Omega_{p}-\phi_{p} \dot{\theta}_{p}\right] \mathbf{e}_{3}^{p}
\end{aligned}
$$

where $\Omega_{p}$ is the constant angular rotational speed of the pinion. The velocity vectors for the gear are identical except with components for the gear. The kinetic energy stored in the gear-shaft bodies is

$$
T_{m e s h}=\frac{1}{2}\left(\boldsymbol{\omega}_{p}^{T} \mathbf{J}_{p} \boldsymbol{\omega}_{p}+\boldsymbol{\omega}_{g}^{T} \mathbf{J}_{g} \boldsymbol{\omega}_{g}+\dot{\mathbf{r}}_{p}^{T} m_{p} \dot{\mathbf{r}}_{p}+\dot{\mathbf{r}}_{g}^{T} m_{g} \dot{\mathbf{r}}_{g}\right)
$$

To model each of the four bearings, we introduce a massless rigid ring that represents the bearing race attached to the housing. Associated with this rigid ring are six degrees-of-freedom: three for translation of the ring center and three for rotation of the ring relative to its orientation on the undeformed housing. The bearing translational coordinates are $x_{b i}, y_{b i}$, and $z_{b i}$, and the rotational coordinates are $\phi_{b i}, \theta_{b i}$, and $\beta_{b i}$, where $i$ "element of symbol from set notation" $\{1,2,3,4\}$. Bearing 1 is attached to point $A_{p}$ on the pinion shaft, bearing 2 is attached to point $A_{g}$ on the gear shaft, bearing 3 is attached to point $B_{p}$ on the pinion shaft, and bearing 4 is attached to point $B_{g}$ on the gear shaft.

Each bearing (rigid ring) is connected to a gear-shaft body through its bearing stiffness matrix. The bearing deformation vector is defined as the relative deflection of the bearing rigid ring with respect to the point where it is attached on the gear-shaft body. This is illustrated in Figure 17, where the bearing race is the ring connected directly to the housing. The rollers in Figure 17 are for visualization; they are replaced by the bearing stiffness matrix shown by the spring stiffnesses in Figure 17. The bearing deflection vectors of the four bearings are

$$
\begin{aligned}
\mathbf{d}_{p}^{A} & =\left[\theta_{p}\left(L_{p}^{A}-e_{p}\right)+x_{p}-x_{b 1}\right] \mathbf{E}_{1}+\left[\phi_{p}\left(e_{p}-L_{p}^{A}\right)+y_{p}-y_{b 1}\right] \mathbf{E}_{2}+z_{p}-z_{b 1} \mathbf{E}_{3} \\
\mathbf{d}_{p}^{B} & =\left[\theta_{p}\left(L_{p}^{B}-e_{p}\right)+x_{p}-x_{b 2}\right] \mathbf{E}_{1}+\left[\phi_{p}\left(e_{p}-L_{p}^{B}\right)+y_{p}-y_{b 2}\right] \mathbf{E}_{2}+z_{p}-z_{b 2} \mathbf{E}_{3} \\
\mathbf{d}_{g}^{A} & =\left[\theta_{g}\left(L_{g}^{A}-e_{g}\right)+x_{g}-x_{b 3}\right] \mathbf{E}_{1}+\left[\phi_{g}\left(e_{g}-L_{g}^{A}\right)+y_{g}-y_{b 3}\right] \mathbf{E}_{2}+z_{g}-z_{b 3} \mathbf{E}_{3} \\
\mathbf{d}_{g}^{B} & =\left[\theta_{g}\left(L_{g}^{B}-e_{g}\right)+x_{g}-x_{b 4}\right] \mathbf{E}_{1}+\left[\phi_{g}\left(e_{g}-L_{g}^{B}\right)+y_{g}-y_{b 4}\right] \mathbf{E}_{2}+z_{g}-z_{b 4} \mathbf{E}_{3}
\end{aligned}
$$

The bearings resist tilting as well. The relative angular deflections between the bearing races and the 
gear-shaft bodies at each of the four bearings are, for small angles,

$$
\begin{aligned}
\gamma_{p}^{A} & =\left(\phi_{p}-\phi_{b 1}\right) \mathbf{E}_{1}+\left(\theta_{p}-\theta_{b 1}\right) \mathbf{E}_{2}+\left(\beta_{p}-\beta_{b 1}\right) \mathbf{E}_{3} \\
\gamma_{p}^{B} & =\left(\phi_{p}-\phi_{b 2}\right) \mathbf{E}_{1}+\left(\theta_{p}-\theta_{b 2}\right) \mathbf{E}_{2}+\left(\beta_{p}-\beta_{b 2}\right) \mathbf{E}_{3}, \\
\gamma_{g}^{A} & =\left(\phi_{g}-\phi_{b 3}\right) \mathbf{E}_{1}+\left(\theta_{g}-\theta_{b 3}\right) \mathbf{E}_{2}+\left(\beta_{g}-\beta_{b 3}\right) \mathbf{E}_{3}, \\
\gamma_{g}^{B} & =\left(\phi_{g}-\phi_{b 4}\right) \mathbf{E}_{1}+\left(\theta_{g}-\theta_{b 4}\right) \mathbf{E}_{2}+\left(\beta_{g}-\beta_{b 4}\right) \mathbf{E}_{3} .
\end{aligned}
$$

Collecting the 24 components of the vectors in Eqs. (8)-(11), the bearing relative translational and angular deflection vectors are defined as

$$
\boldsymbol{\Gamma}_{p}^{A}=\left[\begin{array}{c}
\mathbf{d}_{p}^{A} \cdot \mathbf{E}_{1} \\
\mathbf{d}_{p}^{A} \cdot \mathbf{E}_{2} \\
\mathbf{d}_{p}^{A} \cdot \mathbf{E}_{3} \\
\gamma_{p}^{A} \cdot \mathbf{E}_{1} \\
\gamma_{p}^{A} \cdot \mathbf{E}_{2} \\
\gamma_{p}^{A} \cdot \mathbf{E}_{3}
\end{array}\right], \boldsymbol{\Gamma}_{p}^{B}=\left[\begin{array}{c}
\mathbf{d}_{p}^{B} \cdot \mathbf{E}_{1} \\
\mathbf{d}_{p}^{B} \cdot \mathbf{E}_{2} \\
\mathbf{d}_{p}^{B} \cdot \mathbf{E}_{3} \\
\gamma_{p}^{B} \cdot \mathbf{E}_{1} \\
\gamma_{p}^{B} \cdot \mathbf{E}_{2} \\
\gamma_{p}^{B} \cdot \mathbf{E}_{3}
\end{array}\right], \boldsymbol{\Gamma}_{g}^{A}=\left[\begin{array}{c}
\mathbf{d}_{g}^{A} \cdot \mathbf{E}_{1} \\
\mathbf{d}_{g}^{A} \cdot \mathbf{E}_{2} \\
\mathbf{d}_{g}^{A} \cdot \mathbf{E}_{3} \\
\gamma_{g}^{A} \cdot \mathbf{E}_{1} \\
\gamma_{g}^{A} \cdot \mathbf{E}_{2} \\
\gamma_{g}^{A} \cdot \mathbf{E}_{3}
\end{array}\right], \boldsymbol{\Gamma}_{g}^{B}=\left[\begin{array}{c}
\mathbf{d}_{g}^{B} \cdot \mathbf{E}_{1} \\
\mathbf{d}_{g}^{B} \cdot \mathbf{E}_{2} \\
\mathbf{d}_{g}^{B} \cdot \mathbf{E}_{3} \\
\gamma_{g}^{B} \cdot \mathbf{E}_{1} \\
\gamma_{g}^{B} \cdot \mathbf{E}_{2} \\
\gamma_{g}^{B} \cdot \mathbf{E}_{3}
\end{array}\right]
$$

where each bearing deflection vector is $6 \times 1$. For the pinion bearing connected to $A_{p}$, the first element $\mathbf{d}_{p}^{A} \cdot \mathbf{E}_{1}$, the second element $\mathbf{d}_{p}^{A} \cdot \mathbf{E}_{2}$, and the third element $\mathbf{d}_{p}^{A} \cdot \mathbf{E}_{3}$ are the translational bearing displacements. Similarly, the fourth element $\gamma_{p}^{A} \cdot \mathbf{E}_{1}$, the fifth element $\boldsymbol{\gamma}_{p}^{A} \cdot \mathbf{E}_{2}$, and the sixth element $\boldsymbol{\gamma}_{p}^{A} \cdot \mathbf{E}_{3}$ are the angular bearing displacements.

Bearing stiffness matrices are fully populated $6 \times 6$ matrices. At point $A_{p}$, the bearing stiffness matrix is $\mathbf{K}_{p}^{A}$. The second, third, and fourth bearing stiffness matrices are $\mathbf{K}_{p}^{B}, \mathbf{K}_{g}^{A}$, and $\mathbf{K}_{g}^{B}$, respectively.

The potential energy stored by the bearing stiffnesses are

$$
\begin{aligned}
& V_{b 1}=\frac{1}{2} \boldsymbol{\Gamma}_{p}^{A^{T}} \mathbf{K}_{p}^{A} \boldsymbol{\Gamma}_{p}^{A}, V_{b 2}=\frac{1}{2} \boldsymbol{\Gamma}_{p}^{B^{T}} \mathbf{K}_{p}^{B} \boldsymbol{\Gamma}_{p}^{B}, \\
& V_{b 3}=\frac{1}{2} \boldsymbol{\Gamma}_{g}^{A^{T}} \mathbf{K}_{g}^{A} \boldsymbol{\Gamma}_{g}^{A}, V_{b 4}=\frac{1}{2} \boldsymbol{\Gamma}_{g}^{B^{T}} \mathbf{K}_{g}^{B} \boldsymbol{\Gamma}_{g}^{B}
\end{aligned}
$$

and the total potential energy stored in all bearings are $V_{b}=V_{b 1}+V_{b 2}+V_{b 3}+V_{b 4}$. The bearing rings are assumed to be massless, so their kinetic energy is zero.

The total kinetic and potential energy in the system is the sum of potential energy stored in the gear mesh and the bearings, giving,

$$
T=T_{m e s h}, V=V_{m e s h}+V_{b}
$$




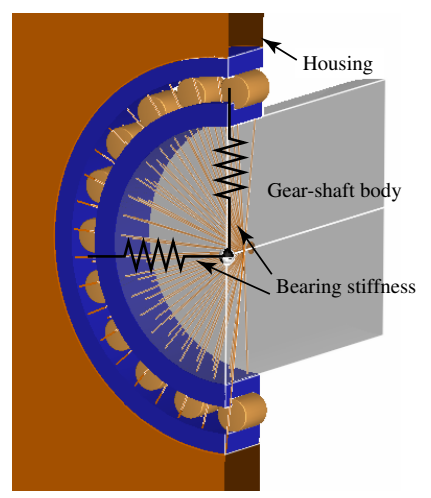

Figure 17: Each fully populated $6 \times 6$ bearing stiffness matrix connects the gear-shaft body to the bearing race. The bearings are fitted in a gearbox housing. The rollers are for visualization; they are replaced in the mathematical model by a stiffness matrix as represented by the spring elements. The lines indicate rigid connections of the nodes that correspond to the surface nodes of the bearing outer race to the six degrees-of-freedom bearing rigid body, which is indicated by the centerline.

The vector of degrees-of-freedom of the gear-shaft bodies is defined as $\mathbf{q}_{s}=\left[\mathbf{q}_{p}, \mathbf{q}_{g}\right]^{T}$, where

$$
\begin{aligned}
& \mathbf{q}_{p}=\left[x_{p}, y_{p}, z_{p}, \phi_{p}, \theta_{p}, \beta_{p}\right]^{T} \\
& \mathbf{q}_{g}=\left[x_{g}, y_{g}, z_{g}, \phi_{g}, \theta_{g}, \beta_{g}\right]^{T}
\end{aligned}
$$

The vectors of degrees-of-freedom of the four bearings are defined as

$$
\begin{aligned}
& \mathbf{q}_{b 1}=\left[x_{b 1}, y_{b 1}, z_{b 1}, \phi_{b 1}, \theta_{b 1}, \beta_{b 1}\right]^{T}, \\
& \mathbf{q}_{b 2}=\left[x_{b 2}, y_{b 2}, z_{b 2}, \phi_{b 2}, \theta_{b 2}, \beta_{b 2}\right]^{T}, \\
& \mathbf{q}_{b 3}=\left[x_{b 3}, y_{b 3}, z_{b 3}, \phi_{b 3}, \theta_{b 3}, \beta_{b 3}\right]^{T}, \\
& \mathbf{q}_{b 4}=\left[x_{b 4}, y_{b 4}, z_{b 4}, \phi_{b 4}, \theta_{b 4}, \beta_{b 4}\right]^{T}
\end{aligned}
$$

and the vector of all the bearing degrees-of-freedom as

$$
\mathbf{q}_{b}=\left[\mathbf{q}_{b 1}, \mathbf{q}_{b 2}, \mathbf{q}_{b 3}, \mathbf{q}_{b 4}\right]^{T}
$$

Lagrange's equations of motion for unconstrained generalized coordinates $\mathbf{q}_{s}$ and $\mathbf{q}_{b}$ give the equations of motion as

$$
\left[\begin{array}{cc}
\mathbf{M}_{s} & \mathbf{0} \\
\mathbf{0} & \mathbf{0}
\end{array}\right]\left(\begin{array}{c}
\ddot{\mathbf{q}}_{s} \\
\ddot{\mathbf{q}}_{b}
\end{array}\right)+\left[\begin{array}{cc}
\mathbf{K}_{s} & \mathbf{K}_{s b} \\
\mathbf{K}_{s b}^{T} & \mathbf{K}_{b}
\end{array}\right]\left(\begin{array}{c}
\mathbf{q}_{s} \\
\mathbf{q}_{b}
\end{array}\right)=\left(\begin{array}{c}
\mathbf{f}_{s} \\
\mathbf{f}_{b}
\end{array}\right)
$$

The matrix $\mathbf{K}_{s}$ in Eq. (18) contains the stiffness caused by the gear mesh. The matrix $\mathbf{K}_{b}$ contains the stiffness caused by the bearings, and the stiffness matrix $\mathbf{K}_{s b}$ contains the coupling terms between gearshaft and bearing degrees-of-freedom. The mass matrix is singular because the masses of the rigid bearing 
rings have been neglected. The mass matrix $\mathbf{M}_{s}$ contains the inertia of the gear-shaft bodies. $\mathbf{K}_{b}$ is $24 \times 24$. $\mathbf{M}_{s}$ and $\mathbf{K}_{s}$ are $12 \times 12$. The vector $\mathbf{f}_{s}$ includes external loading, such as the driving and absorbing torques on the pinion and gear shafts. Also, the tooth surface modifications $h_{i}$ appear in $\mathbf{f}_{s}$. The Coriolis and centripetal accelerations that arise from the constant rotation speed are neglected because the speed is not high enough in this application for these terms to become significant.

The housing is modeled using finite element analysis. The inertia of the housing is neglected. The housing nodes at the circumference of each bearing outer race are rigidly connected to form the four bearing races used above. The bearing ring degrees-of-freedom $\mathbf{q}_{b 1}, \mathbf{q}_{b 2}, \mathbf{q}_{b 3}$, and $\mathbf{q}_{b 4}$ dictate the motion of these nodes. This procedure condenses the housing degrees-of-freedom of the nodes at the circumference of each bearing race into $\mathbf{q}_{b}$. The part of the housing stiffness matrix corresponding to $\mathbf{q}_{b}$ is $\mathbf{K}_{c}$. The housing nodes that are not related to the bearings have the vector of degrees-of-freedom $\mathbf{q}_{h}$, and the corresponding stiffness matrix $\mathbf{K}_{h}$. The remaining part of the housing stiffness matrix is $\mathbf{K}_{c h}$, which couples the bearing degrees-of-freedom $\mathbf{q}_{b}$ to the housing degrees-of-freedom $\mathbf{q}_{h}$. A generic housing to illustrate the condensation procedure is shown in Figure 18. The lines show the housing nodes that are condensed into bearing 1 (rigid disk).

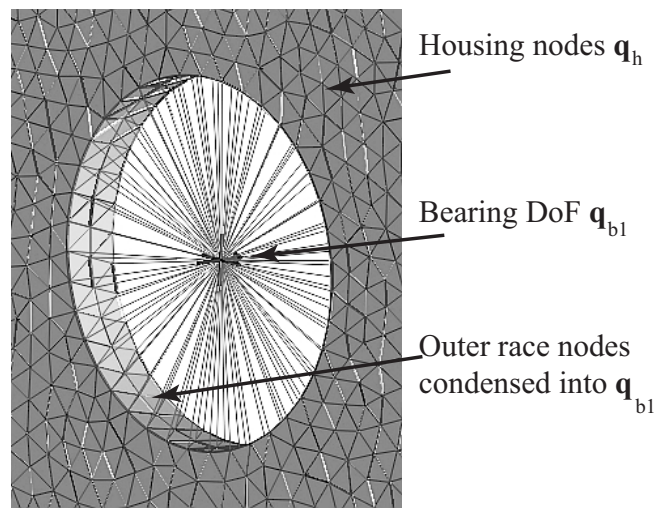

Figure 18: A generic housing illustrates the condensation procedure. The lines indicate rigid connections of the nodes that correspond to the surface nodes of the bearing outer race to the six degrees-of-freedom bearing rigid body, which is indicated by the centerline.

There are no applied forces on the housing nodes except at the condensation points of the bearings, which is $\mathbf{f}_{c}$. Thus, the equation of motion of the housing with free boundary conditions at the bearing degrees-of-freedom $\mathbf{q}_{b}$ is

$$
\left[\begin{array}{cc}
\mathbf{K}_{h} & \mathbf{K}_{c h} \\
\mathbf{K}_{c h}^{T} & \mathbf{K}_{c}
\end{array}\right]\left(\begin{array}{l}
\mathbf{q}_{h} \\
\mathbf{q}_{b}
\end{array}\right)=\left[\begin{array}{l}
\mathbf{0} \\
\mathbf{f}_{c}
\end{array}\right]
$$


The gear-shaft bodies are connected to the housing by way of the bearing stiffness matrix by requiring that the forces at the housing connection points are equal and opposite to the forces at the bearings, that is, $\mathbf{f}_{b}=-\mathbf{f}_{c}$. Solving for $\mathbf{f}_{c}$ from Eq. (19), substituting $\mathbf{f}_{b}=-\mathbf{f}_{c}$ in Eq. (18), and eliminating $\mathbf{q}_{b}$ from Eq. (18) gives

$$
\mathbf{M}_{s} \ddot{\mathbf{q}}_{s}+\left[\mathbf{K}_{s}-\mathbf{K}_{s b}\left(\mathbf{K}_{b}+\mathbf{K}_{c}-\mathbf{K}_{c h} \mathbf{K}_{h}^{-1} \mathbf{K}_{c h}^{T}\right)^{-1} \mathbf{K}_{s b}^{T}\right] \mathbf{q}_{s}=\mathbf{0}
$$

Equation (20) incorporates the housing flexibility, without the housing degrees-of-freedom and housing inertia, into the equations of motion of the gears, shafts, and bearings.

Equation (20) requires the part of the stiffness matrix that describes bearing flexibility $\mathbf{K}_{c}, \mathbf{K}_{c h}$, and $\mathbf{K}_{h}$. These matrices are not readily accessible from commercial finite element codes because they relate to specific housing and bearing nodes. Nevertheless, a part of the stiffness matrix in Eq. (20) can be found using an influence coefficient matrix [64, 65]. The influence coefficient matrix is

$$
\mathbf{C}=\left[\mathbf{K}_{c}-\mathbf{K}_{c h} \mathbf{K}_{h}^{-1} \mathbf{K}_{c h}^{T}\right]^{-1}
$$

The elements of $\mathbf{C}$ are found from the finite element model of the housing by applying a unit force to each degree-of-freedom at the connection points, set in $\mathbf{f}_{c}$, one at a time, and calculating the deflection of all of the degrees-of-freedom at the connection points $\mathbf{q}_{b}$. The $j^{\text {th }}$ element in the $i^{\text {th }}$ column, that is, $\mathbf{C}^{<i, j>}$ is

given by the displacement $\mathbf{q}_{b}^{<j>}$ calculated from Eq. (19) when there is a unit force at $\mathbf{f}_{c}^{<i>}=1$, where $j=1, \ldots, n$.

\subsubsection{Dynamic Analysis Using the Lumped-Parameter Model}

Tooth surface modifications and gear displacements introduce nonlinearity as they distort the contact pattern of the gear teeth from the nominal design contact pattern. This phenomenon is called partial contact loss and is discussed in detail in [11]. Even though the dynamic analysis in this work is linear, the mean system stiffness depends on the applied torque. To account for the effect of the operating torque, the mean system stiffness matrix is obtained from the nonlinear quasi-static solution of Eq. (20). Linear dynamic analysis of Eq. (20) is performed using this mean value of the system stiffness matrix, which is found by averaging the quasi-statically changing time-dependent system stiffness over a mesh period $T_{\text {period }}$, giving

$$
\overline{\mathbf{K}}_{s}=\frac{1}{T_{\text {period }}} \int_{0}^{T_{\text {period }}} \mathbf{K}_{s}(t) d t
$$

The dynamic excitation is the parametric stiffness fluctuation as a result of a fluctuating number of gear teeth that are in contact with nominal kinematic gear rotation. To model this excitation, the gear- 
shaft displacement vector $\mathbf{q}_{s}$ is first solved quasi-statically from Eq. (20) at several points over a mesh period. The quasi-static system displacement is split into mean $\left(\overline{\mathbf{q}}_{s}\right)$ and fluctuating $\left(\mathbf{w}_{s}(t)\right)$ components by $\mathbf{q}_{s}=\overline{\mathbf{q}}_{s}+\mathbf{w}_{s}(t)$. Substitution of $\mathbf{q}_{s}=\overline{\mathbf{q}}_{s}+\mathbf{w}$ into Eq. (20) and neglecting the product $\left(\mathbf{K}_{s}(t)-\overline{\mathbf{K}}_{s}\right) \mathbf{w}_{s}(t)$ of small quantities gives the approximate linear, time-invariant equations of motion as

$$
\mathbf{M}_{s} \ddot{\mathbf{w}}+\left[\overline{\mathbf{K}}_{s}-\mathbf{K}_{s b}\left(\mathbf{K}_{b}+\mathbf{C}^{-1}\right) \mathbf{K}_{s b}^{T}\right] \mathbf{w}=\left[\overline{\mathbf{K}}_{s}-\mathbf{K}_{s b}\left(\mathbf{K}_{b}+\mathbf{C}^{-1}\right) \mathbf{K}_{s b}^{T}\right] \mathbf{w}_{s}(t)=\mathbf{f}_{w} .
$$

The excitation uses the first 10 harmonics of $\mathbf{f}_{w}$. Damping is light [66] and approximated by constant modal damping ratios after Eq. (23) is transformed into modal coordinates.

The pinion bearings are located at $L_{p}^{A}=120.74 \mathrm{~mm}, L_{p}^{B}=-124.34 \mathrm{~mm}$, and the gear bearings are located at $L_{g}^{A}=120.33 \mathrm{~mm}, L_{g}^{B}=-123.65 \mathrm{~mm}$ from the midpoint of the gear facewidth. The pinion mass is $2.18 \mathrm{~kg}$ and the gear mass is $2.24 \mathrm{~kg}$. The pinion moments of inertia are $J_{p}^{<3,3>}=5.42 \times 10^{-4} \mathrm{~kg}-\mathrm{m}^{2}$ and $J_{p}^{<1,1>}=J_{p}^{<2,2>}=1.7 \times 10^{-2} \mathrm{~kg}-\mathrm{m}^{2}$. For the gear, $J_{g}^{<3,3>}=5.48 \times 10^{-4} \mathrm{~kg}-\mathrm{m}^{2}$ and $J_{g}^{<1,1>}=J_{g}^{<2,2>}=$ $1.8 \times 10^{-2} \mathrm{~kg}-\mathrm{m}^{2}$. Other parameters are provided in Table 1 . The stiffnesses of the gear mesh and the bearings are found from finite element analysis.

Table 6 shows the natural frequencies of the system with cylindrical/ball bearings (Table 2) with and without housing compliance. All vibration modes of the gearbox with housing compliance are visualized in Figure 19. Although these are spur gears, there are modes with axial displacement of the gears. These, however will not be excited because the spur gear mesh does not generate axial thrust forces. Modes 2, 3, 4, and 9 are predominantly axial motions of the gears and shafts. Modes 5 and 6 are predominantly translations of the gear and pinion. Modes 7, 8, 10, and 11 are predominantly tilting of the pinion and gear. Mode 12, shown in Figure 19(k), is the mesh deflection mode, which is the mode where the gear modal displacements are such that most of the potential energy is in the mesh stiffness. The mesh deflection mode is therefore sensitive to the gear mesh stiffness and insensitive to bearing and housing flexibility. The mesh deflection mode is important because the tooth pass excitation excites primarily this mode (the mesh deflection mode natural frequencies are printed in italics in Table 6). The mesh deflection mode persists with little change in natural frequency with and without housing compliance, with values of $3893 \mathrm{~Hz}$ and $3910 \mathrm{~Hz}$, respectively.

Differences in some of the natural frequencies and mode shapes between the lumped-parameter model, finite element model, and experiments, provided in Tables 4 and 6, are expected because the lumpedparameter model does not include the inertia of the housing, therefore, modes from the finite element model and experiments that include structural displacements of the gearbox housing will not be captured 
in the lumped-parameter model. The dynamic transmission error peak at $4449 \mathrm{~Hz}$ in Figure 14 indicates that the peak is from the gear mesh deflection mode, which is within $12 \%$ of the mesh deflection mode natural frequency from the lumped-parameter model. The lumped-parameter model captures the mesh deflection mode with a reasonable accuracy is important because the gear mesh predominantly excites this mode.

Figure 20 shows the dynamic peak-to-peak transmission error from the lumped-parameter and finite element models with and without housing compliance. The change in dynamic transmission errors are negligible with and without housing compliance. This is because the transmission error is the response to gear mesh excitation, and it depends mostly on the mesh deflection mode. Because the mesh deflection mode is similar with and without housing, the dynamic transmission error is similar.

This is not the case, however, for the dynamic bearing forces transmitted to the housing. Figure 21 shows the dynamic bearing reactions with and without housing; including the housing flexibility reduces some peaks and increases others. In addition, the housing flexibility moves the resonant peaks toward lower frequencies because of the greater compliance. The bearing type and housing flexibility both have important impacts on the dynamic bearing forces and moments transmitted to the housing. These are the excitations for the housing noise radiation and the lumped-parameter model must predict them accurately.

\begin{tabular}{ccc}
\hline Compliant housing Hz & Rigid housing Hz & Experiment Hz \\
\hline \hline 576.6 & 975.5 & 780 \\
954.6 & 1000 & - \\
987.7 & 1597 & - \\
1515 & 1711 & - \\
1599 & 1868 & 1779 \\
1793 & 1977 & 2007 \\
1915 & 2736 & 2504 \\
2075 & 2848 & - \\
2356 & 3910 & 3816 \\
2722 & - & 4233 \\
3893 & - & - \\
\hline
\end{tabular}

Table 6: Natural frequencies of the NASA gearbox with rolling element bearings (Table 2) with and without housing flexibility. These frequencies that are in italics indicate the mesh deflection mode.

\subsection{Acoustic Modeling and Analysis of the Gearbox}

This model (D) of the gearbox housing consists of tetrahedral elements that have nearly uniform length of all edges in order to have a reasonable aspect ratio. 


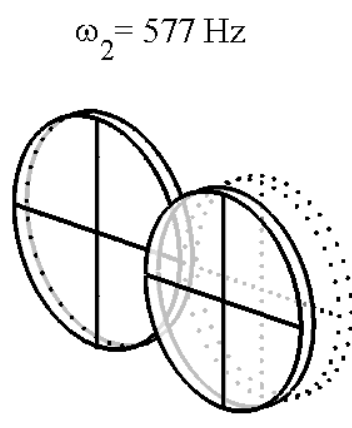

(a)

$$
\omega_{3}=955 \mathrm{~Hz}
$$

$\omega_{4}=988 \mathrm{~Hz}$

$\omega_{5}=1515 \mathrm{~Hz}$

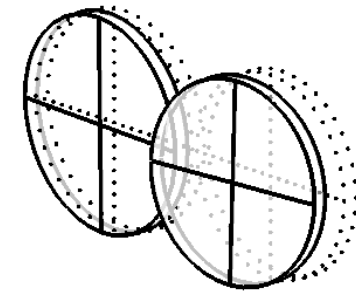

(b)

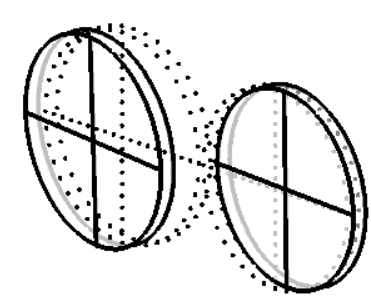

(c)

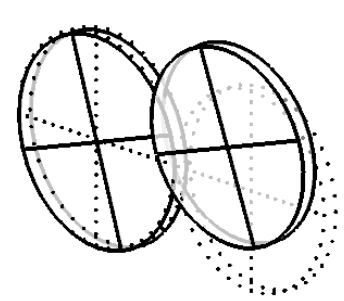

(d)

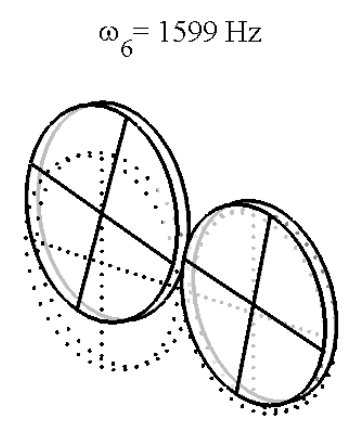

(e)

$$
\omega_{7}=1793 \mathrm{~Hz}
$$

$$
\omega_{8}=1915 \mathrm{~Hz}
$$

$\omega_{9}=2075 \mathrm{~Hz}$



(f)

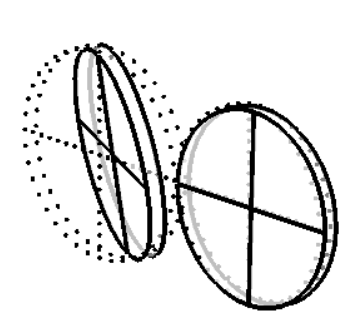

(g)

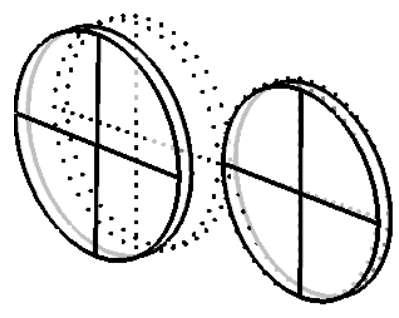

(h)

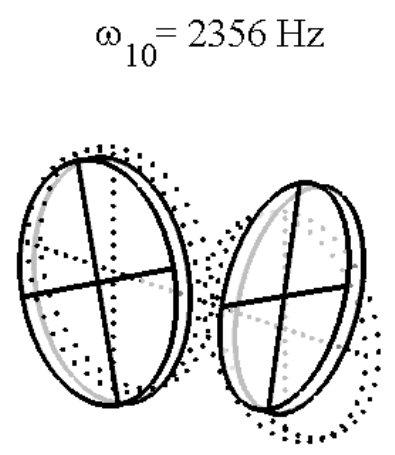

(i)

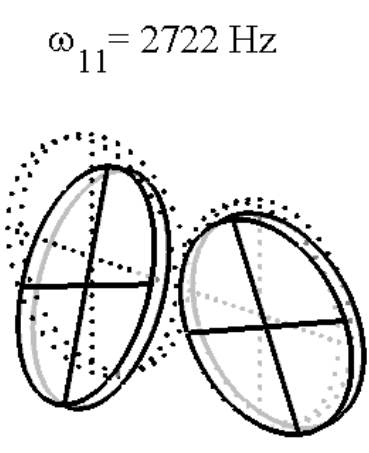

(j)

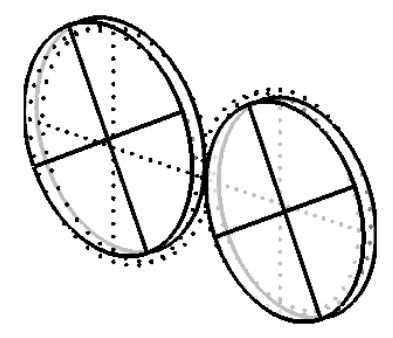

(k)

Figure 19: All vibration modes of the gearbox with cylindrical/ball bearings including housing compliance.

The boundary element model is verified by comparing its results to those from an analytical solution for a monopole sound field as shown in Figure 22. The monopole source is a sphere in which the radius alternately expands and contracts sinusoidally. The far-field pressure radiated by a monopole is [67]

$$
p(r, t)=\frac{i Q \rho c k}{4 \pi r} e^{i(\omega t-k r)}
$$

where $\rho$ is the air density, $c$ is the speed of sound, $k$ is the wave number, $\omega$ is the frequency, and $r$ is the 


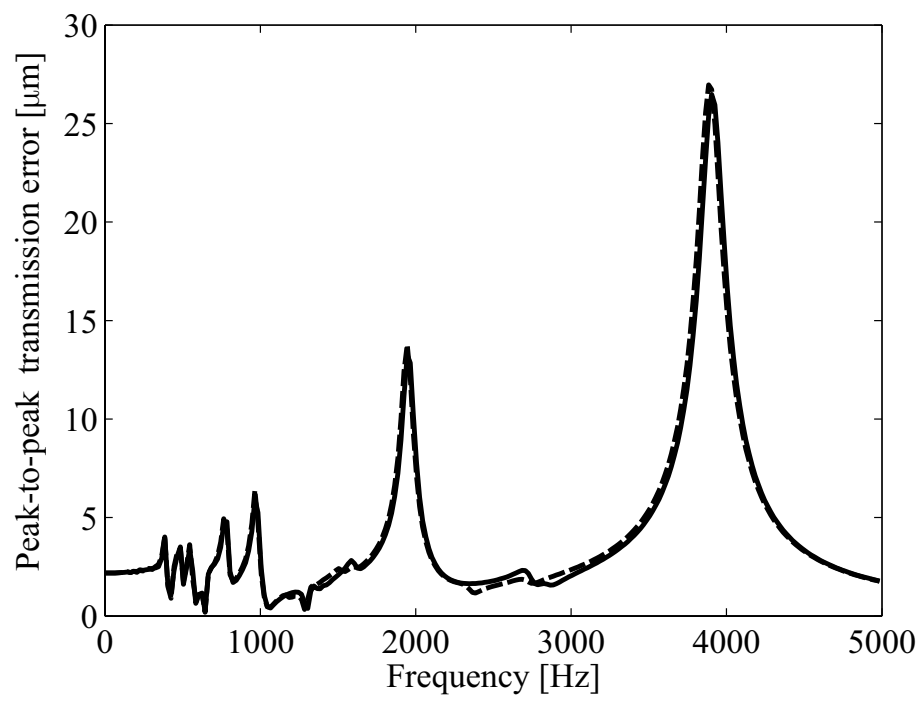

Figure 20: Peak-to-peak dynamic transmission error of four systems. The solid line denotes roller bearings without housing and the dashed line denotes roller bearings with housing.


Figure 21: Dynamic resultant bearing force magnitudes. The solid line denotes rolling bearings without housing and the dashed line denotes rolling bearings with housing. 
local distance from the source. $Q$ is the complex source strength, which is a constant number defined in [67].

The velocity field caused by the monopole in free space at the gearbox surface is calculated theoretically and used as the boundary condition for the boundary element housing model. This fact allows the simulation results to be compared against the theoretical solution for an arbitrary gearbox geometry (Figure $22)$.

The optimal boundary element length (or mesh density) was based on a convergence study. Figure 23 shows the relative error of the computed pressure compared to the theoretical value in Eq. (24) for various element lengths. Result accuracy is improved when the element length is small. When the element length is smaller than $8.64 \mathrm{~mm}$, however, the result accuracy worsens as the round off error becomes significant. The optimal element length is between $8.89 \mathrm{~mm}$ and $10.16 \mathrm{~mm}$ with less than $2 \%$ relative error. This study uses an element length of $9 \mathrm{~mm}$, which results in 50,401 tetrahedral elements.

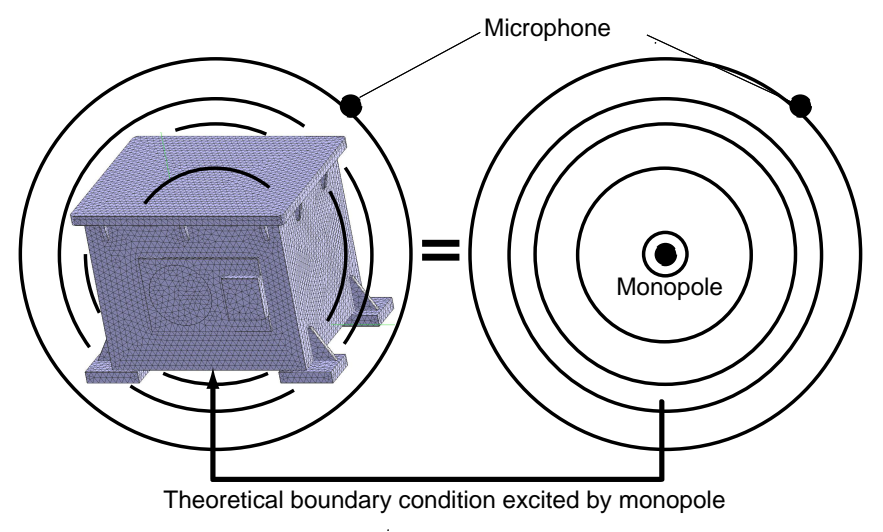

Figure 22: Theoretical solutions used to validate the boundary element housing model. Noise radiated from the housing with the monopole velocity field at the gearbox surface equals to that with a monopole in the free space.

\subsubsection{Sound Pressure and Power Computation Using Transfer Functions}

The dynamic bearing forces and moments that excite the acoustic housing model are known from one of the lumped-parameter (model (B)) or FE/CM models (model (A), Figure 3). Transfer functions from each unit bearing force or moment to sound pressure describe the noise radiation properties of the housing. The superposition of transfer functions for all of the bearing forces and moments is used to predict the sound pressure of the radiated noise [68].

$$
p_{r}(\omega)=\sum H_{s r}(\omega) \cdot F_{s}(\omega)
$$




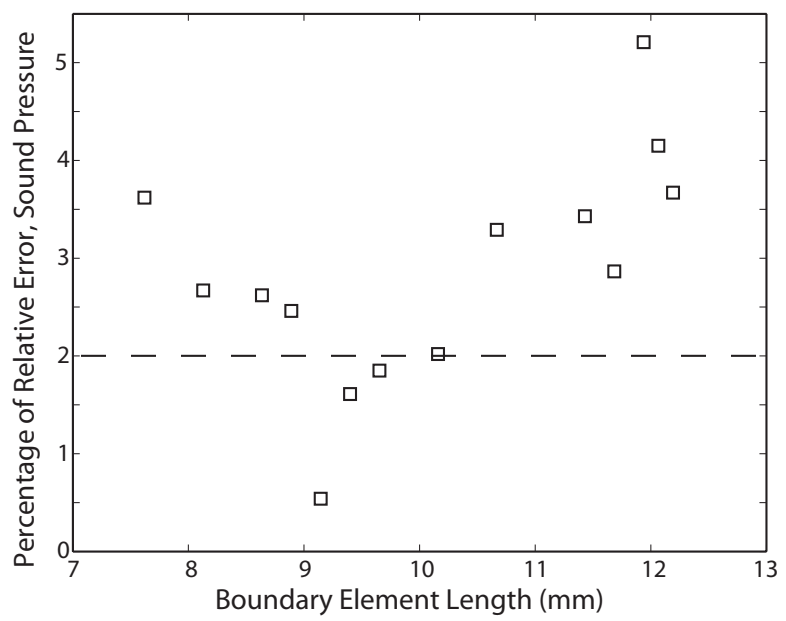

Figure 23: Effects of boundary element length on the relative error of calculated sound pressure compared to the theoretical monopole solution.

where $p_{r}$ is the sound pressure at the receiver, and $\omega$ is the excitation frequency. $H_{s r}$ is the frequency response function of the receiving system, and $F_{s}$ is the force spectrum of each bearing at the source. The computation of these transfer functions is independent of the vibration analysis to determine the bearing reaction forces. Thus, these transfer functions can be applied to any type of bearings or gears and they are calculated only once.

The procedure to calculate transfer functions consists of: a) applying a unit periodic force with the frequency $\omega$ within the specified speed range to each degree-of-freedom $(x, y, z, \phi, \theta, \beta)$ at every bearing, one at a time, to the housing finite element model $(\mathrm{C})$, b) calculating the velocity at the gearbox surface for various speeds within the speed range, and c) computing the sound pressure of the radiated noise at specified locations in the gearbox environment using the computed surface velocity as the boundary condition in the boundary element model. Sound pressure at arbitrary locations outside the gearbox is determined by the superposition of these transfer functions multiplied by corresponding dynamic bearing forces and moments obtained from the lumped-parameter or FE/CM models.

\subsection{Acoustic Result Comparison Against Experiments}

The noise calculated from model (D) was compared against experiments. Two microphones were mounted to measure the sound pressure at $790 \mathrm{~mm}$ directly above the gearbox and are separated horizontally by $180 \mathrm{~mm}$. Only the gearbox with rolling element bearings was compared against measurements (the experimental sound pressure with wave bearings was not available).

Figure 24 shows the frequency spectrum of the measured and computed sound pressure when the mesh 
frequency is $2000 \mathrm{~Hz}$. There is good agreement between the measurements and simulations at the mesh frequency harmonics. Sidebands around the mesh frequency harmonics present in the measured data are not included in the computational model because it does not consider runout and other sideband sources.

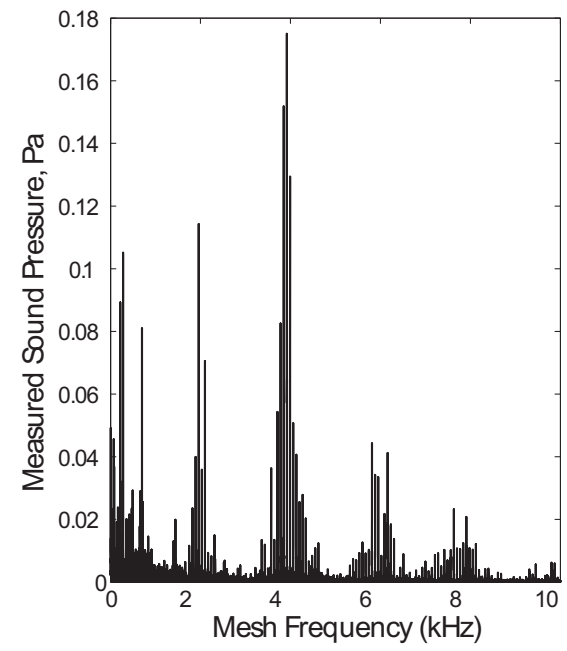

(a)

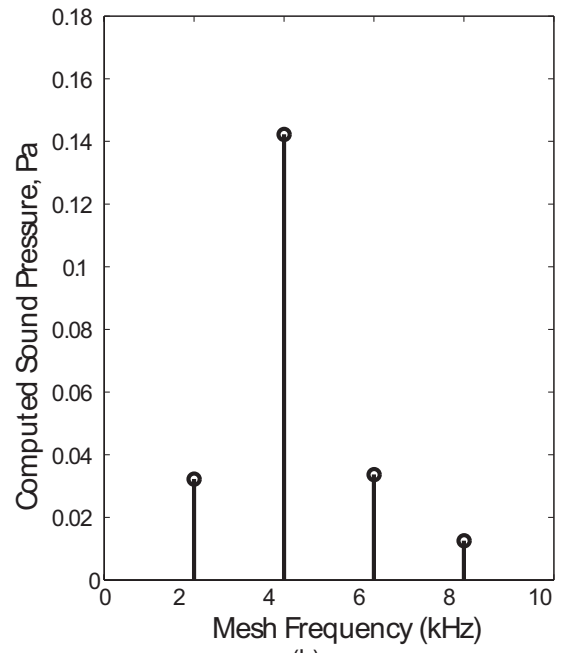

(b)

Figure 24: Frequency spectrum of the (a) measured and (b) simulated sound pressure at microphone 1 when mesh frequency was $2000 \mathrm{~Hz}$.

Figure 25 shows the time averages of the mean-square sound pressure $\left(p_{b}\right)_{r m s}^{2}[69]$ at microphone 1 , which was measured and computed using the boundary element model, where $b$ denotes the frequency band 0-8000 Hz. The parameter $\left(p_{b}\right)_{r m s}^{2}$ consists of the sound pressure at each excitation frequency and its higher harmonics within the band $b$. For each mesh frequency, two different experimental results are shown: the minimum sound pressure including only the mesh frequency harmonics and the maximum sound pressure including the mesh frequency harmonics and all other frequency components-most importantly, the sidebands noted in Figure 24 at the shaft rotation frequency. The simulated sound pressure is within the experimental data range and correlates best with the experimental measurements that include only the mesh frequency harmonics. This is reasonable because the computational model only considers mesh harmonics and not the sidebands.

\subsection{Noise Radiation Properties for Rolling Element and Wave Bearings}

This section compares the effectiveness of rolling element and fluid film wave bearings in reducing noise. Figure 26 compares the sound pressure at the location of microphone 1 excited by the first and second gear mesh frequency harmonics for the gearbox with rolling element bearings (Table 2) and with wave bearings (Table 3). The sound pressure with the wave bearings is generally higher than with rolling 


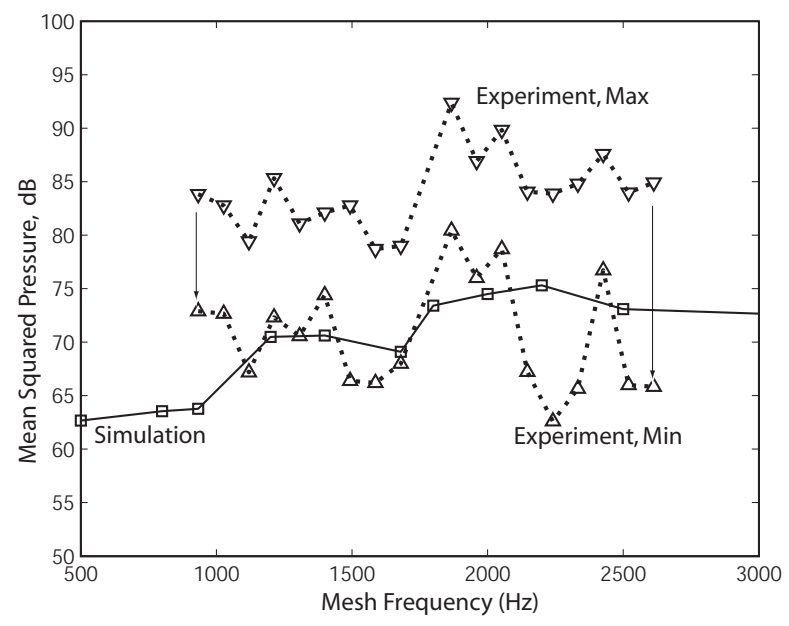

Figure 25: The time average of the experimental $(\cdots)$ and calculated $(-)$ mean squared sound pressure at microphone 1 within mesh frequencies between 500-3000 $\mathrm{Hz}$.

element bearings and the difference is frequency-dependent. The bearing type affects the housing radiated noise by changing the dynamic bearing forces transmitted to the housing. Bearing stiffnesses, damping, and the housing must be accurately modeled for gearbox noise prediction, although they do not significantly affect dynamic transmission error as shown in Figure 20. Figure 26 includes results at selected mesh frequencies because the computation time of radiated noise is one to two orders of magnitude longer than the vibration analysis of the gearbox.

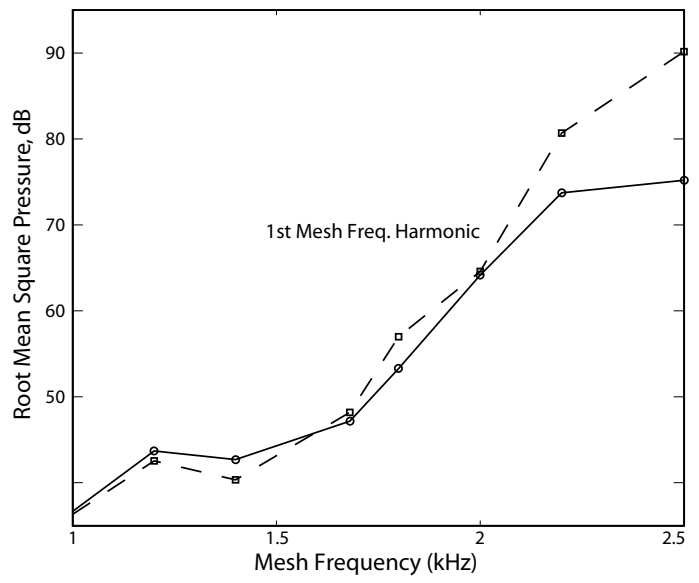

(a)

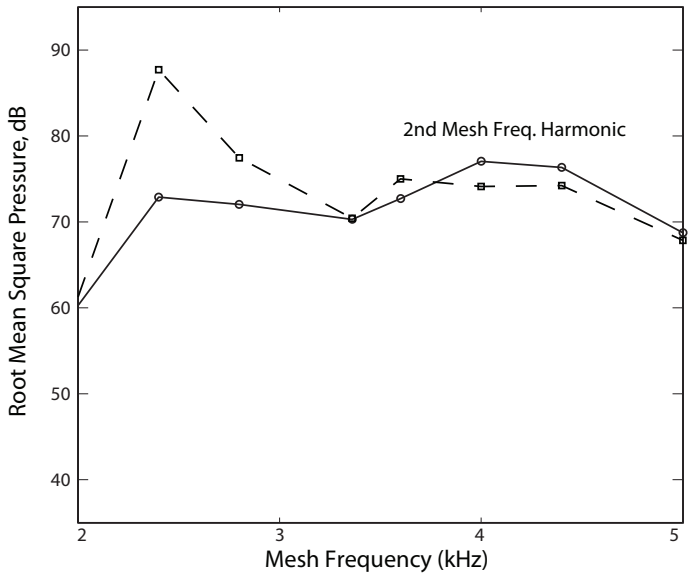

(b)

Figure 26: Sound pressure frequency spectrum with rolling element $(-)$ and wave bearings $(--)$ at the microphone 1 location when mesh frequency is between 1000-2500 $\mathrm{Hz}$ and considering the (a) first and (b) second mesh frequency harmonics.

Sound power is a better measure of gearbox noise than sound pressure because it is independent of 
the measurement location. Sound power measurements in experiments, however, require much effort. In this study, sound power was computed by integrating sound pressure at sufficient locations in a measuring surface that envelops the gearbox. Twenty numerical microphones were used on a spherical surface that surrounds the gearbox based on International Standards Organization (ISO) 3745. The locations of these microphones are listed in [70]. The sound power level $L_{w}$ is computed as

$$
\begin{array}{r}
L_{w}(\mathrm{~dB})=L_{p}+10 \log _{10}\left(\frac{s}{s_{0}}\right)+c_{1}+c_{2} \\
c_{1}(\mathrm{~dB})=-10 \log _{10}\left[\frac{B}{B_{0}}\left(\frac{313.15}{273.15+T}\right)^{\frac{1}{2}}\right] \\
c_{2}(\mathrm{~dB})=-15 \log _{10}\left[\frac{B}{B_{0}}\left(\frac{296.15}{273.15+T}\right)^{\frac{1}{2}}\right]
\end{array}
$$

where $s$ is the area of the measurement surface and $s=s_{0}=1 \mathrm{~m}^{2} ; B_{0}$ is the reference barometric pressure of $101.325 \mathrm{kPa}$; $\mathrm{B}$ is the barometric air pressure during measurements, which is assumed to be the same as $B_{0} ; T=20^{\circ} C$ is the air temperature during measurement; and $L_{p}$ is the weighted surface sound pressure level over the measurement surface in decibels, which gives

$$
\begin{array}{r}
L_{p}(\mathrm{~dB})=10 \log _{10}\left[\frac{1}{N}\left(\sum_{i=1}^{N} 10^{0.1\left(L_{p, i}+W\right)}\right)\right] \\
L_{p, i}=20 \log _{10}\left(\frac{p_{i}}{p_{0}}\right)
\end{array}
$$

where $N$ is the number of microphone positions; $W$ is the weighting function applied by the filter at the frequency of analysis; $p_{i}$ is the measured root mean square pressure in $\mathrm{Pa}$; and $p_{0}=2 \times 10^{-5} \mathrm{~Pa}$. The A-weighting filter (ISO 3745 standard [70]) is used in this study.

The sound power radiated from the gearbox is also compared between wave and rolling element bearings in Figure 27. The first six harmonics of gear mesh frequency are considered in the transfer function calculation; a two-dimensional wave bearing model is used $[48,49]$. The sound power of the gearbox with rolling element and wave bearings is speed-dependent. The radiated gearbox sound power with rolling element bearings is lower than that with fluid film wave bearings, in general, within the speed range of interest. Therefore, there is a noise reduction benefit for this system when using rolling element bearings.

\section{Conclusions}

A combination of vibration and acoustic models addresses the vibro-acoustic propagation of gear dynamics. It includes: 1) either a FE/CM or lumped-parameter gearbox model; 2) a finite element housing 

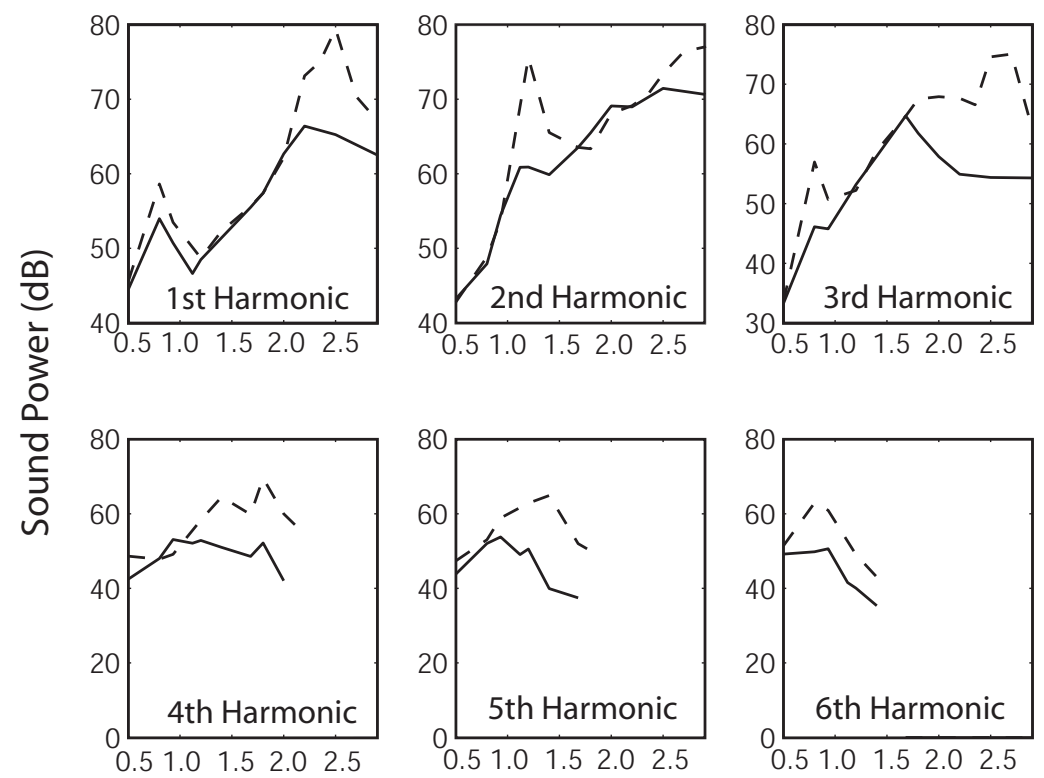

Gear Mesh Frequency, $\mathrm{kHz}$

Figure 27: Sound power of radiated gearbox noise excited by bearing forces with rolling element $(-)$ and fluid film wave bearings $(--)$ for the first six harmonics of gear mesh frequency. The A-weighting filter (ISO 3745 standard [70]) is used to adjust sound pressure levels.

model; and 3) an acoustic boundary element housing model.

The key steps of the noise radiation analysis consist of:

1. Computing dynamic bearing forces using one of the FE/CM or lumped-parameter gearbox models;

2. Computing housing surface velocities excited by the dynamic bearing forces obtained from step 1;

3. Analyzing noise radiation of the housing using the surface velocity calculated from step 2.

This approach can be implemented using conventional analysis software other than the specific choices in this work.

The transfer function method determines sound pressure and sound power independent of bearing type and gear parameters. The transfer functions are calculated only once and then used in conjunction with separately calculated bearing forces and moments. This approach allows for efficient optimization studies to be conducted to reduce noise.

In this work, we compared experimental and theoretical solutions for a pair of spur gears. The predicted natural frequencies of the entire gearbox agreed with the measurements and the radiated noise with rolling element bearings correlated well with the experiments. This work showcases the capability of the computational procedure to accurately estimate gearbox vibration and noise radiation. 
The results show that:

1. Off-diagonal stiffness terms of the rolling element bearing matrices significantly affect gearbox dynamic response.

2. The housing flexibility has only a small impact on the gear dynamics. It affects the critical bearing forces and moments that are influential for noise radiation. Accurate boundary element modeling of the housing is important for noise computation.

3. Use of the wave bearings analyzed here produces slightly higher noise levels than rolling element bearings. For this system, there is not a clear advantage from a noise perspective to using wave bearings for the speed range of interest.

\section{Acknowledgments}

This study was supported by the National Aeronautics and Space Administration (NASA) through contract NNC08CB08C and conducted at Ohio State University. The authors thank the National Renewable Energy Laboratory for supporting the completion of this work. This work was also supported by the U.S. Department of Energy under Contract No. DE-AC36-08GO28308.

\section{References}

[1] E. Mucchi, A. Vecchio, Acoustical signature analysis of a helicopter cabin in steady-state and run up operational conditions, Measurement 43 (2010) 283293.

[2] F. Hoffmann, R. Maier, P. Janker, F. Hermle, A. Berthe, Helicopter interior noise reduction by using active gearbox structs, Proceedings of the 12th AIAA/CEAS Aerospace Conference.

[3] L. Dozio, W. Corbetta, E. Vigono, A. Forghieri, G. Ghiringhelli, F. Cenedese, Active solutions for the reduction of the transmission of structure-borne noise to the cabin structure on a a109 mockup, Proceedings of ISMA.

[4] S. Viswamurthy, R. Ganguli, An optimization approach to vibration reduction in helicopter rotors with multiple active trailing edge flaps, Aerospace Science and Technology 8 (3) (2004) 185-194.

[5] S. Hirsch, V. Jayachandran, J. Q. Sun, Structural-acoustic control for quieter aircraft interior-smart trim technology, 199842 (2) (Composite Structures) 189202. 
[6] R. Randall, Detection and diagnosis of incipient bearing failure in helicopter gearboxes, Engineering Failure Analysis II (2004) 177190.

[7] S. He, R. Singh, G. Pavic, Effect of sliding friction on gear noise based on a refined vibro-acoustic formulation, Journal of Noise Control Engineering 56 (3) (2008) 164-175.

[8] T. C. Lim, R. Singh, Statistical energy analysis of a gearbox with emphasis on the bearing path, Journal of Noise Control Engineering 37 (2) (1991) 63-69.

[9] T. C. Lim, R. Singh, A review of gear housing dynamics and acoustic literature, NASA Contractor Report 185148.

[10] S. M. Vijayakar, Calyx User's Manual, Advanced Numerical Solutions LLC, Hilliard, Ohio, 43026 USA, http://www.ansol.us/Manuals/Helical3DManual.pdf.

[11] T. Eritenel, R. G. Parker, An investigation of tooth mesh nonlinearity and partial contact loss in gear pairs using a lumped-parameter model, Mechanism and Machine Theory 56 (2012) 28-51.

[12] Coustyx 1.9.3804, http://www.ansol.us/Products/Coustyx.

[13] S. A. Hambric, A. D. Hanford, M. R. Shepherd, R. L. Campbell, E. C. Smith, Rotorcraft transmission noise path model, including distributed fluid film bearing impedance modeling, NASA Technical Report.

[14] F. Dimofte, M. P. Proctor, D. P. Fleming, T. G. Keith, Jr, Wave fluid film bearing tests for an aviation gearbox, NASA Technical Report NASA/TM2000-209766.

[15] F. Dimofte, Wave journal bearing with compressible lubricant; part i: The wave bearing concept and a comparison to the plain circular bearing, STLE Tribology Transaction 38 (1) (1995) 153160.

[16] F. Dimofte, H. E. Addy, Jr., Preliminary experimental results of a three wave journal air bearing, Proceedings of Advanced Earth-to-Orbit Propulsion Technology Conference 11 (1994) 375384.

[17] F. Dimofte, Wave journal bearing; part i: Analysis, NASA Contractor Report 195431.

[18] F. B. Oswald, D. P. Townsend, M. J. Valco, R. H. Spencer, R. J. Drago, J. W. Lenski, Influence of gear design parameters on gearbox radiated noise, Tech. Rep. ARL TR-381, NASA (1994). 
[19] Y. Guo, R. G. Parker, Stiffness matrix calculation of rolling element bearings using a finite element/contact mechanics model, Mechanism and Machine Theory 51 (2012) 32-45.

[20] S. M. Vijayakar, A combined surface integral and finite element solution for a three-dimensional contact problem, International Journal for Numerical Methods in Engineering 31 (1991) 524-546.

[21] R. G. Parker, S. M. Vijayakar, T. Imajo, Non-linear dynamic response of a spur gear pair: Modelling and experimental comparisons, Journal of Sound and Vibration 237 (3) (2000) 435-455.

[22] R. G. Parker, V. Agashe, S. M. Vijayakar, Dynamic response of a planetary gear system using a finite element/contact mechanics model, Journal of Mechanical Design 122 (3) (2000) 304-310.

[23] V. K. Ambarisha, R. G. Parker, Nonlinear dynamics of planetary gears using analytical and finite element models, Journal of Sound and Vibration 302 (2007) 577-595.

[24] C. G. Cooley, R. G. Parker, S. M. Vijayakar, A frequency domain finite element approach for threedimensional gear dynamics, ASME Journal of Vibration and Acoustics 133 (4) (2011) 041004.

[25] Ansys 14.0, http://www.ansys.com/.

[26] R. Gunda, Boundary element acoustics and the fast multipole method (fmm), Sound and Vibration.

[27] C.-J. Bahk, R. Parker, Analytical solution for the nonlinear dynamics of planetary gears, ASME Journal of Computational and Nonlinear Dynamics 6 (2) (2011) 021007.

[28] G. Liu, R. G. Parker, Dynamic modeling and analysis of tooth profile modification of multi-mesh gears, ASME Journal of Mechanical Design 130 (2008) 121402.

[29] G. Liu, R. G. Parker, Impact of tooth friction and its bending effect on gear dynamics, Journal of Sound and Vibration 320 (4-5) (2008) 1039-1063. doi:10.1016/j.jsv.2008.08.021.

[30] A. Kahraman, S. M. Vijayakar, Effect of internal gear flexibility on the quasi-static behavior of a planetary gear set, Journal of Mechanical Design 123 (3) (2001) 408-415.

[31] G. Liu, R. Parker, Nonlinear dynamics of idler gearsets, Nonlinear Dynamics 53 (2008) 345-367.

[32] G. Liu, R. G. Parker, Nonlinear, parametrically excited dynamics of two-stage spur gear trains with mesh stiffness fluctuation, Proceedings of the Institution of Mechanical Engineers, Part C: Journal of Mechanical Engineering ScienceDoi: 10.1177/0954406212447509. 
[33] Y. Guo, R. G. Parker, Dynamic analysis of planetary gears with bearing clearance, ASME Journal of Computational and Nonlinear Dynamics 7 (3) (2012) 031008.

[34] A. Singh, Load sharing behavior in epicyclic gears: physical explanation and generalized formulation, Mechanism and Machine Theory 45 (2010) 511-530.

[35] A. Singh, Epicyclic load sharing map - development and validation, Mechanism and Machine Theory 46 (2011) 632-646.

[36] Y. Guo, R. G. Parker, T. Eritenel, T. M. Ericson, Vibration propagation of gear dynamics in a gearbearing-housing system using mathematical modeling and finite element analysis, Tech. rep., NASA Contract NNC08CB03C (2011).

[37] D. J. Inman, Engineering Vibration, 2nd Edition, Prentice Hall, 2000.

[38] T. A. Harris, Rolling bearing analysis, 3rd Edition, John Wiley and Sons, Inc., 1990.

[39] E. P. Gargiulo, Jr., A simple way to estimate bearing stiffness, Mechine Design (1980) 107-110.

[40] M. F. While, Rolling element bearing vibration transfer characteristics: Effect of stiffness, Journal of Applied Mechanics 46 (1979) 677-684.

[41] A. B. Jones, Analysis of stresses and deflections, New Departure Engineering Data.

[42] A. Palmgren, Ball and roller bearing engineering, 3rd Edition, SKF industries, 1959.

[43] J. Brandlein, P. Eschmann, L. Hasbargen, K. Weigand, Ball and roller bearings: theory, design and application, John Wiley and Sons, 1999.

[44] T. J. Royston, I. Basdogan, Vibration transmission through self-aligning (spherical) rolling element bearings: Theory and experiment, Journal of Sound and Vibration 215 (5) (1998) 997-1014.

[45] J. Kraus, J. J. Blech, S. G. Braun, In situ determination of rolling bearing stiffness and damping by modal analysis, Journal of Vibration, Acoustics, Stress, and Reliability in Design 109 (1987) 235-240.

[46] K. Ishida, T. Matsuda, M. Fukui, Effect of gearbox on noise reduction of geared device, Proceedings of the International Symposium on Gearing and Power Transmissions, Tokyo (1981) 13-18. 
[47] A. M. Mitchell, F. B. Oswald, H. H. Coe, Testing of uh-60a helicopter transmission in nasa lewis 2240kw (3000-hp) facility, NASA Technical Paper 2538 (Document ID: E-2801; NAS 1.60:2538; NASATP-2538).

[48] A. Hanford, Wave Journal Bearing Dynamic Coefficients Users Manual, aRL/Penn State (2009).

[49] R. L. a. Campbell, Distributed journal bearing dynamic coefficients for structural finite element models, Proceedings of ASME IMECENCA-43770.

[50] G. W. Blankenship, R. Singh, Dynamic force transmissibility in helical gear pairs, Mechanism and Machine Theory 30 (3) (1995) 323-339.

[51] G. W. Blankenship, R. Singh, A new gear mesh interface dynamic model to predict multi dimensional force coupling and excitation, Mechanism and Machine Theory 30 (1) (1995) 43-57.

[52] M. Salzer, J. Smith, D. Welbourn, Simulation of noise from gears when varying design and manufacturing parameters, Proceedings of the World Congress on Gearing 1 (1977) 297-308.

[53] A. Kahraman, Effect of axial vibrations on the dynamics of a helical gear pair, Journal of Vibration and Acoustics 115 (1) (1993) 33-39.

[54] A. Andersson, L. Vedmar, A dynamic model to determine vibrations in involute helical gears, Journal of Sound and Vibration 260 (2) (2003) 195-212.

[55] P. Velex, M. Maatar, A mathematical model for analyzing the influence of shape deviations and mounting errors on gear dynamic behavior, Journal of Sound and Vibration 191 (5) (1996) 629-660.

[56] T. Eritenel, R. G. Parker, Three-dimensional nonlinear vibration of gear pairs, Journal of Sound and Vibration 331 (15) (2012) 3628-3648.

[57] T. F. Conry, A. Seireg, Mathematical programming technique for evaluation of load distribution and optimal modification for gear systems, Journal of Engineering for Industry 95 (4) (1973) 1115-1122.

[58] Y. Ogawa, S. Matsumura, H. Houjoh, T. Sato, K. Umezawa, Rotational vibration of a spur gear pair considering tooth helix deviation: Development of simulator and verification, JSME International Journal, Series C 43 (2) (2000) 423-431. 
[59] A. Attia, Deflection of spur gear teeth cut in thin rims, Journal of Engineering for Industry 86 (1963) 333-342.

[60] P. Velex, P. Sainsot, An analytical study of tooth friction excitations in errorless spur and helical gears, Mechanism and Machine Theory 37 (7) (2002) 641-658.

[61] W. D. Mark, Analysis of the vibratory excitation of gear systems: Basic theory, Journal of the Acoustic Society of America 63 (1978) 1409-1430.

[62] E. Buckingham, Analytical mechanics of gears, Dover, 2011.

[63] D. W. Dudley, Handbook of Practical Gear Design, McGraw-Hill Book Company, 1984.

[64] E. L. Wilson, The static condensation algorithm, International journal for numerical methods in engineering 8 (1) (1973) 198-203.

[65] R. R. Craig, M. Bampton, Coupling of substructures for dynamic analyses, The American Institute of Aeronautics and Astronautics 6 (7) (1968) 1313-1319.

[66] H. N. Ozguven, D. R. Houser, Dynamic analysis of high speed gears by using loaded static transmission error, Journal of Sound and Vibration 125 (1) (1988) 71-83.

[67] L. E. Kinsler, A. R. Frey, A. B. Coppens, J. V. Sanders, Fundamentals of Acoustics, Wiley, New York, 1982.

[68] J. Plunt, Strategy for transfer path analysis (tpa) applied to vibro-acoustic systems at medium and high frequencies, ISMA 23.

[69] C. Hansen, Noise control: from concept to application, Taylor and Francis, 2005.

[70] International Standards Organization (ISO) 3745: 2003 Acoustics - Determination of sound power levels of noise sources using sound pressure - Precision methods for anechoic and hemi-anechoic rooms. 